\title{
Assessing the Hydrodynamic Response of the Mar Menor Lagoon to Dredging Inlets Interventions through Numerical Modelling
}

\author{
Miriam García-Oliva ${ }^{1, *(\mathbb{D})}$, Ángel Pérez-Ruzafa ${ }^{1}$, Georg Umgiesser ${ }^{2,3}$ (D), William McKiver ${ }^{2}$ (D), \\ Michol Ghezzo ${ }^{2}$ (D), Francesca De Pascalis ${ }^{2}$ (D) and Concepción Marcos ${ }^{1}$ \\ 1 Department of Ecology and Hydrology, University of Murcia, 30100 Murcia, Spain; angelpr@um.es (Á.P.-R.); \\ cmarcos@um.es (C.M.) \\ 2 Institute of Marine Science-National Research Council (ISMAR-CNR), Arsenale-Tesa 104, Castello 2737/F, \\ 30122 Venice, Italy; georg.umgiesser@ismar.cnr.it (G.U.); william.mckiver@ve.ismar.cnr.it (W.M.); \\ michol.ghezzo@ve.ismar.cnr.it (M.G.); francesca.depascalis@ve.ismar.cnr.it (F.D.P.) \\ 3 Marine Research Institute, Klaipeda University, Herkaus Manto str. 84, LT-92294 Klaipeda, Lithuania \\ * Correspondence: miriam.garcia22@um.es; Tel.: +34-868-88-39-84
}

Received: 9 May 2018; Accepted: 17 July 2018; Published: 20 July 2018

\begin{abstract}
The Mar Menor lagoon has been subjected to high anthropogenic pressures. Among them, in the early 1970s, dredging and enlargement of one of the inlets to make a navigable channel has had strong consequences on the hydrology, ecology, and fisheries of the lagoon. In recent years, changes in agricultural practices have induced an eutrophication process, leading to loss of water quality. As a solution, some management proposals have included dredging of the inlets in order to increase the water renewal. However, these proposals did not take into account the negative effects of previous experiences nor the consequences on environmental conditions of the lagoon and therefore on biological processes. The purpose of this work is to assess the effect that proposed mitigation measures, could have on the hydrodynamic conditions and discuss its possible ecological consequences. A three-dimensional (3D) numerical model has been used to simulate the lagoon under different dredging scenarios, covering different dredging depths and extensions. The simulated current fields and fluxes through the inlets, as well as water renewal times have been compared for the different scenarios. It is found that some of the considered scenarios take the system beyond the threshold of sustainability, where the modified current dynamics could affect sediment transport, beach dynamics and fishing capacities in a significant way. Water exchange with the Mediterranean is also strongly affected, with consequences for species connectivity, and a homogenization of the water renewal times that could lead to loss of ecosystem heterogeneity and structural complexity. The study demonstrates the utility of numerical models as effective tools for the management of coastal areas.
\end{abstract}

Keywords: coastal lagoon; dredging inlets; hydrodynamics; numerical modelling; water renewal time

\section{Introduction}

Coastal lagoons are areas of ecological and economic importance with a high spatial and temporal variability, which makes them complex systems of high productivity in most cases [1,2]. Their economic importance, not only depends on the existence of fisheries and related activities [3], but also the various tourism and recreational activities that have appeared over recent years, increasing the stress on the existing ecosystems [4-7]. Pumping and dredging activities related to coastal works devoted to increase tourist facilities in lagoons can have negative consequences on water and sediment quality, and therefore on biological assemblages, and eventhough these were intended to be improved for tourist appeal [8]. At the same time, the hydrodynamic behaviour of coastal lagoons plays a crucial role in their 
functioning, not only in terms of water quality conditions, but also in terms of environmental range for species inhabiting the lagoons, species connectivity, and fishing capacities [3,9-11]. Therefore, it is necessary to consider carefully any measure with potential impacts on the hydrodynamics of the lagoons, such as dredging, pumping sand, building new structures, or any other human intervention of this kind.

The issues of hydro-sedimentary processes in lagoons and enclosed bays are important in terms of the coastal management and, as such, they have been often treated so in the literature. Some examples can be found in the works by Wu et al. [12], who applied a three-dimensional Finite Volume Community Ocean Model (3D FVCOM) model together with empirical models of the sediment transport and measurements of the surface sediment concentrations in a macro-tidal environment, the Bay of Fundy (Canada). They found that the sediment transport in the upper part of the Bay of Fundy (Minas Basin, Minas Passage and Chignecto Bay) is strongly influenced by the shear stress parameters. A previous study by Davidson-Arnott et al. [13] also focused on the Bay of Fundy and analysed the hydro-sedimentary processes at Chignecto Bay and Cumberland Basin through field measurements of flow and sediments concentration as well as surveys. The authors found that flows at the saltmarsh depended on the bathymetry and marsh surface, and that a large amount of sediments moved through the marsh margin with sediment deposition controlled by waves. The authors mentioned the ecological importance of the saltmarshes vegetation in the primary productivity of waterfowl habitats as well as their relevance for sediment exchange and accumulation of contaminants. Regarding areas with high pressures from human activities, the study by Suanez \& Bruzzi [14] analysed the impacts of different kinds of engineering structures (soft and hard) used for the dune restoration and coastal protection in the Rhone Delta, which hosts salt industries and tourism activities. It was found that the efficiency of each system mainly depended on the sediment supply at each location. The authors also proposed three management scenarios and analysed the associated issues in terms of hydrosedimentary processes. Grifoll et al. [15] applied the three-dimensional Regional Ocean Modeling System (3D ROMS) numerical model to evaluate the water renewal conditions in Bilbao Harbour in terms of the cleaning capacity for the water contamination, highlighting the importance of the hydrodynamics in understanding the water renewal processes due to their close relationships. Water renewal was computed by the local flushing time. An integrated index of risk for each pollutant was calculated, considering the different activities at the harbour, such as oil and chemicals activities, construction, shipyard, and dredging. It was highlighted that the use of 3D models provides a more realistic representation in this case, where the renewal patterns are affected by the changes in the vertical currents structure.

However, most of these works are carried out in estuarine systems or with strong tidal ranges in which the tidal forces or the flow of fresh water introduces a marked unidirectional character in the flows and physico-chemical and biological gradients. In fact, it is precisely that uni-versus multidirectional character and the restrictions on communication with the adjacent sea imposed by physical barriers that are among the main characteristics that determine the differences between estuaries and coastal lagoons [16].

In the case of coastal lagoons, numerical models have been used to provide a better understanding of the underlying physical trends governing the effects caused by changing their main features, including their isolation degree. For example, numerical models have been widely applied to describe the water exchange of the lagoons with the open sea or other coastal bodies, given its importance for different biogeochemical and ecological processes.

In a study by Umgiesser et al. [17] the three-dimensional (3D) Shallow water hydrodynamic finite element model (SHYFEM) model was used to compare 10 Mediterranean lagoons in terms of water exchange and mixing behaviour. The authors found that the exchange with the open sea highly influenced the transport scale times, although the wind can also enhance the exchange mechanisms in lagoons with more than one inlet. Based on this model, Ferrarin et al. [18] assessed the impact of climate change on temperature, salinity, as well as water exchange and mixing efficiency. The study 
predicts that choked lagoons, like the Mar Menor, would have shorter renewal times because the exchange with the Sea increased due to climate change. The increase of the lagoon volume would not be as large as the increase in the exchange. Therefore, choked lagoons will shift towards restricted types. On the other hand, leaky types of lagoons will move towards restricted types too, because the water exchange will not increase as much as the volume of the lagoon, resulting in a higher water renewal time (WRT). They conclude that there will be a homogenisation of the lagoon types in terms of their hydrological conditions, resulting in changes to the biogeochemical conditions and a loss of biodiversity. More recently, Umgiesser et al. [19] performed a study to analyse the dependency of the variability of water exchange on different hydrographical and climatic factors in the Curonian lagoon. The study analyses the seasonal variations of the water renewal and it demonstrates that there is no influence of density-driven circulations on the water exchange.

What concerns the impact of dredging scenarios on water renewal times, a study at the Obidos lagoon has been carried out in [20], in which the simulations were done using the three-dimensional Modelo Hidrodinâmico (3D MOHID) model and included a sand transport module. This study delimits the range of changes in the WRT due to the dredging, which can reach up to a $50 \%$ reduction is some areas. Jeyar et al. [21] developed a two-dimensional (2D) model of the Nador lagoon through the UFV-SWM model in order to analyse changes in the water renewal times due to the relocation of the inlet as a measure of the improvement of water quality in the lagoon. One recent study is the work carried out by Teatini et al. [22], where a numerical model of the Venice lagoon was used together with various techniques (Computational Fluid Dynamics (CFD) models, field measurements) in order to analyse the effects of dredging the channels on the water exchange from the aquifer existing underneath the lagoon and the consequences for water quality in terms of pollutants transport. They also analysed the effects of the depression waves produced by vessels in groundwater pumping.

This study focuses on the Mar Menor as a representative case due to the serious environmental issues that have arisen over recent decades. One of the more important transformations was linked to the hydrodynamic changes due to the enlargement of the El Estacio inlet in 1972 to construct a navigable channel up to $30 \mathrm{~m}$ wide and $5 \mathrm{~m}$ deep. This provoked an increase in water renewal rates, reduction of salinity, and extreme temperatures, thus allowing colonisation by new species, in a process of "Mediterranisation" of the lagoon with important effects on sediment characteristics and a drop in fishing yields [23-25]. More recently, and correlated with changes in agricultural practices in the drainage basin with the introduction of intensively irrigated crops, the alteration of the nutrient entry regime has produced a series of changes that has affected the trophic status and the ecological integrity of the lagoon [26]. Dredging the channels connecting the lagoon with the open sea has been proposed as a possible mitigation measure for the improvement of the water quality, but the effectiveness and potential impacts of such a measure has to be analysed cautiously. Therefore, the aim of this study is to analyse the impact of dredging activities on the hydrodynamic conditions in the Mar Menor, in order to determine the environmental consequences of such changes.

An earlier modelling study of the Mar Menor was carried out by De Pascalis et al. [27], in which the 2D SHYFEM model was used to analyze the effects of climate change on the hydrodynamic, salinity and temperature conditions. Ghezzo et al. [28], considered the Mar Menor, as well as part of the Mediterranean Sea, using the 2D SHYFEM model coupled with a Lagrangian particle tracking module in order to assess the species connectivity between the lagoon and the sea and inside the lagoon. More recently, the thesis by López-Castejón [29] has given insight into the hydrodynamic mechanisms in the Mar Menor in terms of the spatial and temporal variability of water levels, currents, water exchange with the Sea and water renewal times using the 3D ROMS model.

The novelty of this study is the use of the 3D SHYFEM model as a tool for a detailed analysis of the impacts of dredging interventions in the channels, covering a range of depths and extensions, on the currents regime, the water exchange volumes and the water renewal times, as well as the potential effects on the ecosystem of the Mar Menor. 


\section{Materials and Methods}

\subsection{Study Site}

The Mar Menor is a choked hypersaline lagoon located in the South-East of Spain and it represents one of the largest coastal lagoons in the Mediterranean. The lagoon surface is $136.1 \mathrm{~km}^{2}$, while the mean and maximum depths are 4.4 and $7.0 \mathrm{~m}$, respectively, resulting in a total volume of $598.8 \mathrm{hm}^{3}$ [17]. The lagoon is separated from the Mediterranean Sea by La Manga, a sand barrier of approximately $23 \mathrm{~km}$ length, although three inlets act as openings where the exchange with the sea happens. These channels are named Las Encañizadas (El Ventorrillo, La Torre, and El Charco), El Estacio, and Marchamalo, from North to South.

Regarding the temperature and salinity regimes within the lagoon, its partial isolation leads to higher seasonal variations compared with the open sea. Salinity ranges between 38 and 51 and the temperature usually oscillates between values close to $10^{\circ} \mathrm{C}$ in winter and $31{ }^{\circ} \mathrm{C}$ in summer $[25,30]$. Usually a higher salinity is observed inside the lagoon with respect to the Sea, mainly due to the high evaporation rates and the low quantity of annual rainfall. In terms of salinity, the higher values observed inside the lagoon with respect to that of the Sea are mainly due to the evaporation rates of approximately $900 \mathrm{~mm}$ /year, significantly higher than the annual rainfall, which is under $300 \mathrm{~mm} /$ year [27]. Therefore, the water entering the system both from the open sea or fresh sources compensates this difference in hydrological balance [31,32]. This idea of hypersalinity being favored as a result of having evaporation volumes higher than the amount of freshwater input was also found in the study by Webster et al. [33], which is focused on the choked hypersaline Coorong lagoon. The authors also mention the role of the restricted connectivity in this phenomenon.

The Mar Menor shows a North behavior with a tidal range of $\pm 10 \mathrm{~cm}$ and a circulation mainly driven by the wind [27]. The 2D scenarios analyzed by De Pascalis et al. [27] for the main wind regimes, eastern (NE, E, SE) and SW directions, highlighted two different behaviors of the lagoon's circulation. Winds from eastern directions divide the basin horizontally in northern (anticlockwise) and central-southern (clockwise) circulation cells, while the SW wind divides the basin longitudinally. The influence of winds was confirmed by an additional scenario forced only with tides where the currents were almost absent (below the order of $1 \mathrm{~mm} / \mathrm{s}$ ), except in the inlets areas [27].

The water level difference between the lagoon and the sea and the wind can also have a strong influence on salt fluxes, as identified in research carried out by Zemlis et al. [34] on the Curonian lagoon.

\subsection{Numerical Model (Simulation Set Up)}

The numerical model used in this study was SHYFEM, developed at the Institute of Marine Sciences in Venice (ISMAR-CNR) [35]. The model was originally applied to the Shallow Water Equations, but more recently adapted to the case of the 3D primitive equations [36]. Details of the 3D model equations can be found in Ferrarin et al. [37]. A finite element approach was used for the horizontal spatial discretisation and a semi-implicit algorithm is used for the time integration [35]. The use of an unstructured triangular mesh gave good adaptation to complex geometries [38].

Salinity and temperature were calculated through the transport and diffusion equations. The temperature was given by the radiation through the water surface, and the salinity was computed in terms of the evaporation and precipitation through the water surface as well as the freshwater inputs from rivers and streams [35]. A second-order explicit scheme based on the total variational diminishing (TVD) method was used to solve the transport and diffusion equation, as in the work by Ferrarin et al. [37].

The wind and bottom drag stress terms were expressed as quadratic terms [17]. An algorithm for the wetting and drying fronts was also included in a mass conservative way in order to account for the flooding phenomena at the sandflats [38]. 


\subsection{Application to Mar Menor}

The 3D version of the SHYFEM model was applied to simulate the Mar Menor lagoon (Spain). The 3D model allows one to take account of the bi-directional flows in the surface and bottom of the lagoon.

The shoreline and the bathymetry used in the model domain were obtained by the Department of Ecology and Hydrology of the University of Murcia through the digital version of the Nautical Charts in the area of interest. An area of sandbanks in the Encañizadas channel has also been included in the bathymetry. The extension of the sandbanks has been represented through the analysis of the aerial photographs from the period of the simulation as elements with a certain elevation over the sea level (approximately $0.2 \mathrm{~m}$ over mean sea level) but partially submerged during the tidal oscillation.

At the open sea boundary, water levels have been imposed and forced by observed data measured at the South-West Mediterranean area by the Floater system of the Spanish Ports Authority (Puertos del Estado) during 2009-2010. A water level gradient was also imposed from south to north to simulate an observed southward longshore current with a flow of $0.08 \mathrm{~m} / \mathrm{s}$, following the approach in Ghezzo et al. [10].

Regarding the main watercourses flowing into the lagoon, shown in Figure 1, their discharges have been implemented as point sources close to the land boundary and calculated through the Rational Equation (initially) adopting a uniform runoff coefficient of $6.5 \%$ along the basin, according to De Pascalis et al. [27]. Previously, a test was performed by using a smaller coefficient (1.6\%), as suggested by Hesse et al. [39], but the results showed a poorer adjustment of the salinity field data than the ones from the finally adopted runoff coefficient.

For some of the water courses (Alcázares, Albujón, Miranda, Miedo, Del Beal, Ponce y Carrasquilla) salinity conditions were imposed from the data available from the report carried out by Perez-Ruzafa et al. [40].

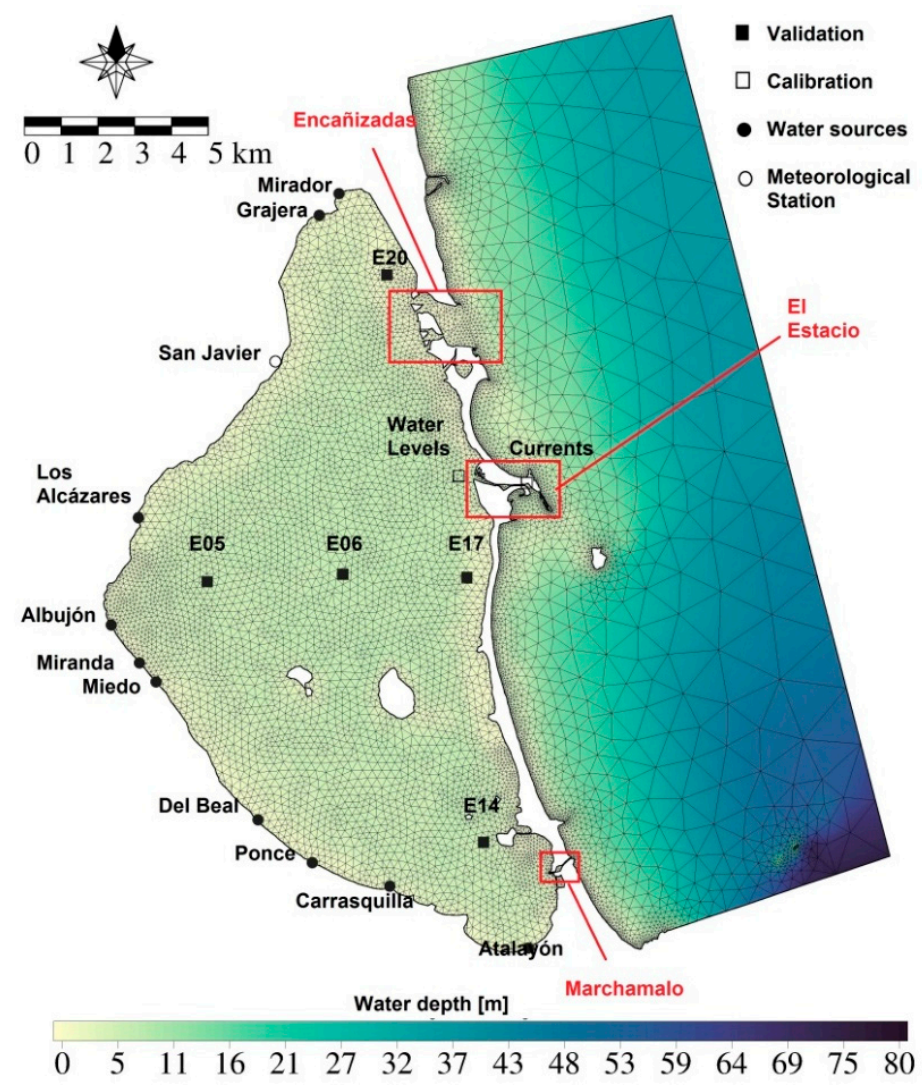

Figure 1. Model domain, bathymetry, channels, water courses, and stations for meteorological data, calibration and validation. 
Hourly meteorological conditions for rain, wind, air temperature, cloud coverage, humidity, and solar radiation during the period of the simulation have been obtained from the Spanish Meteorological Office (AEMET) station at the Academia General del Aire in San Javier. (see Figure 1).

The salinity and temperature conditions at the open sea boundary were imposed using 3D data taken from the Copernicus project for the Mediterranean area [41] during the simulation period. A linear interpolation has been applied to the boundary conditions. The initial conditions of salinity and temperature inside the lagoon were obtained through field data measured by the University of Murcia, previously used in the study by Ghezzo et al. [10].

The model was set up in baroclinic mode as there are density gradients in the lagoon that give rise to baroclinic currents. The full baroclinic pressure terms and the advection and diffusion of temperature and salinity were computed. The choice for the algorithm calculating the evaporation in the model is the same scheme as in the AREG (Adriatic Regional Model) model presented in the study by Oddo et al. [42].

The simulation period was set from 1 January 2009 until 31 December 2010, in order to include a spin-up period, as well as the seasonal variations of the results and the water renewal times, approximately estimated as one year in previous studies [17,31].

Regarding the time integration, the model used an adaptive time-step, and the minimum and maximum values of the time-step was set to 0.001 and $300 \mathrm{~s}$, respectively. Also, a limit of 0.8 was imposed on the Courant number for stability in the numerical computation.

The triangular unstructured grid covering the model domain consisted of 16,133 elements (8865 nodes) with element sizes ranging from 10 to $1800 \mathrm{~m}$, as can be seen from Figure 1, and distributed over 10 vertical zeta-layers. The thickness of the upper seven layers was $1 \mathrm{~m}$ uniformly, while for the deeper three layers the bottom values of the layers were 13, 20, and $36 \mathrm{~m}$. As usual for zeta-layers, only the surface layer was variable in thickness over time.

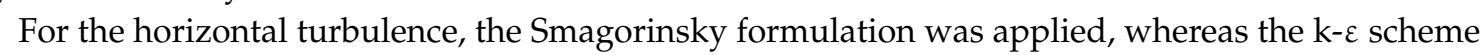
of the Global Ocean Turbulence Model (GOTM) [43] was used for the turbulence closure of the vertical viscosities. The wind drag coefficient was set to a value of 0.0025 , as in the 2D model of the Mar Menor by De Pascalis et al. [27].

\subsubsection{Calibration and Validation}

The seabed roughness was calibrated by comparing the model results with the hydrodynamic data (current speeds and water levels) at El Estacio channel, measured from 25 December 1985 to 25 April 1986 [44]. The seabed roughness was defined by the Strickler formula, which depends on the water depth, and evaluated at each time-step. Different values of the Strickler coefficient, ranging from 27 to $36 \mathrm{~m}^{1 / 3} / \mathrm{s}$, were applied uniformly to the basin and tested during the aforementioned period of 4 months. As can be seen from Table 1, a Strickler coefficient of $30 \mathrm{~m}^{1 / 3} / \mathrm{s}$ gave a better adjustment for the water levels, while there was good agreement for the current velocity for the Strickler coefficient of $27 \mathrm{~m}^{1 / 3} / \mathrm{s}$. In a previous study by De Pascalis et al. [27], lower coefficients were found to better represent the conditions at El Estacio channel, where the observations were taken, implying that the coefficient of $27 \mathrm{~m}^{1 / 3} / \mathrm{s}$ would be more representative of this local area. However, for the rest of the basin they used a coefficient of $30 \mathrm{~m}^{1 / 3} / \mathrm{s}$ and found that it provided good agreement between the model results and the field data. The seabed within the lagoon was mostly covered by Caulerpa Prolifera during the period of the simulations, as can be seen from the study by Pérez-Ruzafa et al. [45], therefore the Strickler coefficient could be considered spatially constant. Therefore, a value of $30 \mathrm{~m}^{1 / 3} / \mathrm{s}$ of the Strickler coefficient was considered uniform for the whole domain in the simulations here presented. 
Table 1. Strickler coefficients for the seabed roughness and coefficients of determination between the model results and field data.

\begin{tabular}{ccc}
\hline Coeff. Strickler $\left(\mathbf{m}^{\mathbf{1 / 3}} \mathbf{s}\right)$ & $\mathbf{R}^{\mathbf{2}}$ Levels & $\mathbf{R}^{\mathbf{2}}$ Velocities \\
\hline 27 & 0.9424 & 0.7560 \\
30 & 0.9426 & 0.7554 \\
32 & 0.9425 & 0.7546 \\
36 & 0.9417 & 0.7523 \\
\hline
\end{tabular}

Table 2 shows the average and standard deviation for the model results and the field data with the Strickler coefficient of $30 \mathrm{~m}^{1 / 3} / \mathrm{s}$. The similar ranges of values found both between the water levels and current speeds for the model and observations depicted the suitability of the model for emulating real conditions.

Table 2. Average values and standard deviation between field data and model results during the simulation period.

\begin{tabular}{ccccc}
\hline & \multicolumn{2}{c}{ Water Level (m) } & \multicolumn{2}{c}{ Current Speed (m/s) } \\
\cline { 2 - 5 } & Observed & Modelled & Observed & Modelled \\
\hline Average & 0.000 & 0.008 & -0.008 & -0.001 \\
Standard Deviation & 0.100 & 0.079 & 0.295 & 0.297 \\
\hline
\end{tabular}

The model results were validated through comparison with salinity and temperature observations taken along the Mar Menor lagoon during the period of the simulation (1 January 2009-31 December 2010). The location of the different stations where the observations were made can be seen in Figure 1. Each station was related to one of the areas in which the lagoon was divided in previous research [30].

Figure 2 shows the comparison between the salinity and temperature at the upper layer $(1 \mathrm{~m}$ thickness) from the model results and the observed values at the aforementioned stations. It can be seen that there is a better agreement for the temperature. The root mean square error (RMSE) between the observed values and the model results at each station is also provided in Figure 2.

It was seen that the model mostly underestimated the observed salinity values. This happened especially during periods when the runoff was larger and more frequent. One cause of this behaviour is the fact that old salt mining areas are present around the lagoon that might bring much more salt into the basin then what is imposed as the salinity concentration in the rivers.

The vertical variations of the salinity and temperature were also compared between the model and the field data. Figures 3 and 4 show the comparison between the vertical profiles of temperature and salinity, respectively, from the model results and the field data. Two different dates in Autumn and Spring were covered in order to account for the seasonality of the results. It can be seen that there was no stratification occurring in general within the lagoon and that the model results reproduced this situation. The model results were in good agreement with the observed measurements. The model reproduced the observations with a maximum error of less than 2 psu and 2 degrees for salinity and temperature, respectively. 


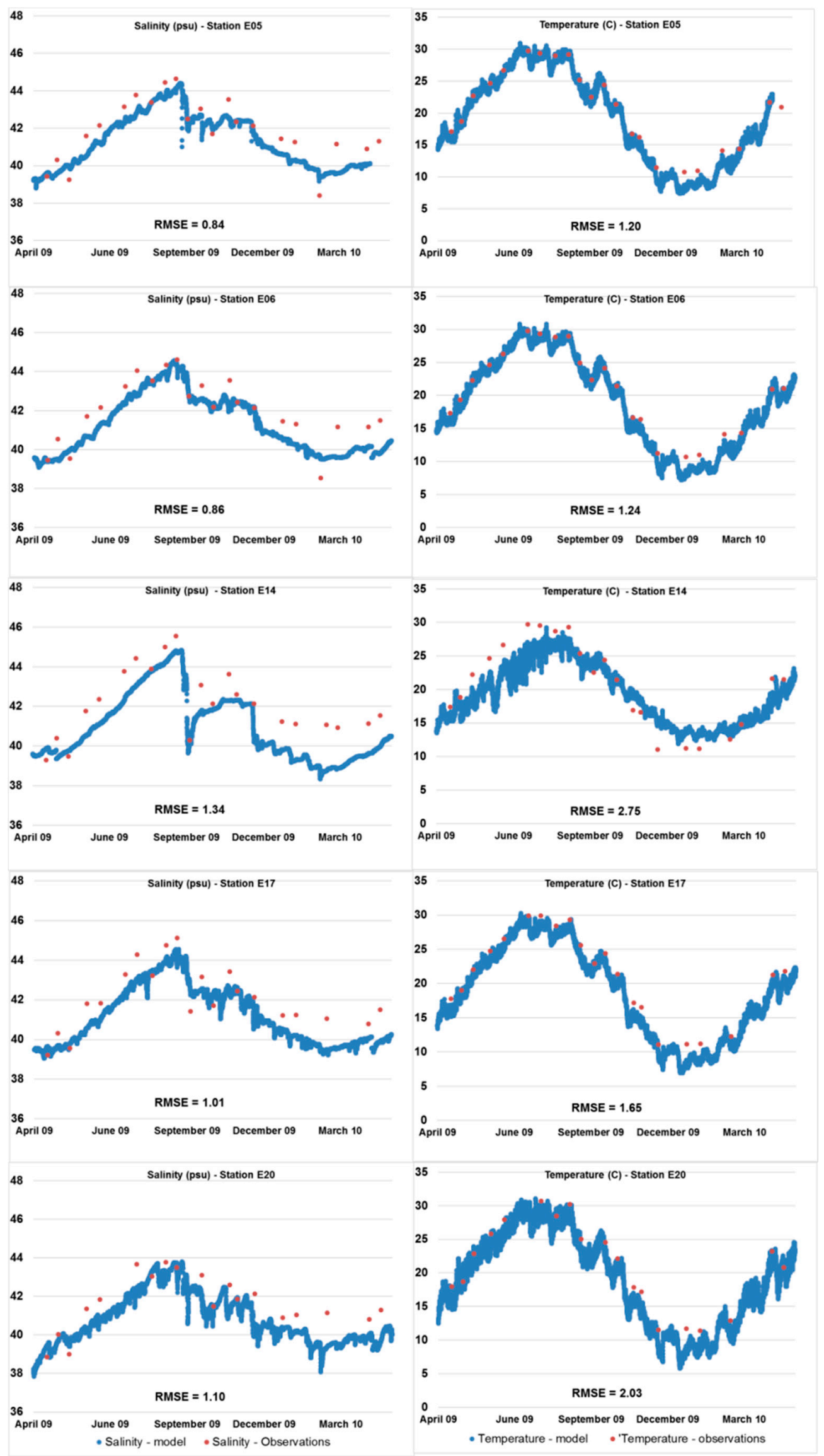

Figure 2. Time series of the modelled (blue curve) and observed (red points) salinity and temperature at the surface layer from different locations. 


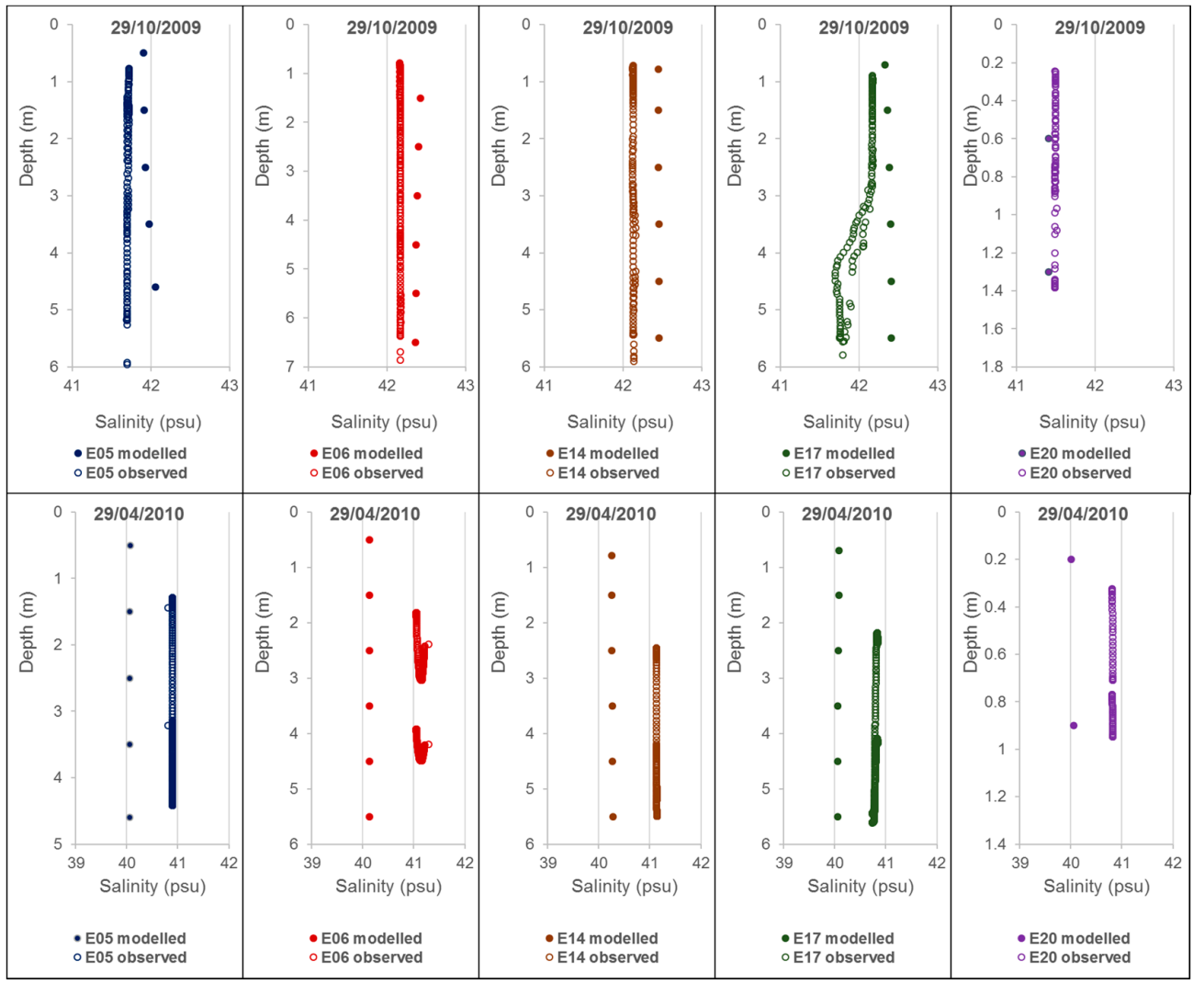

Figure 3. Modelled and observed vertical profiles of salinity on 29 October 2009 and 29 April 2010.

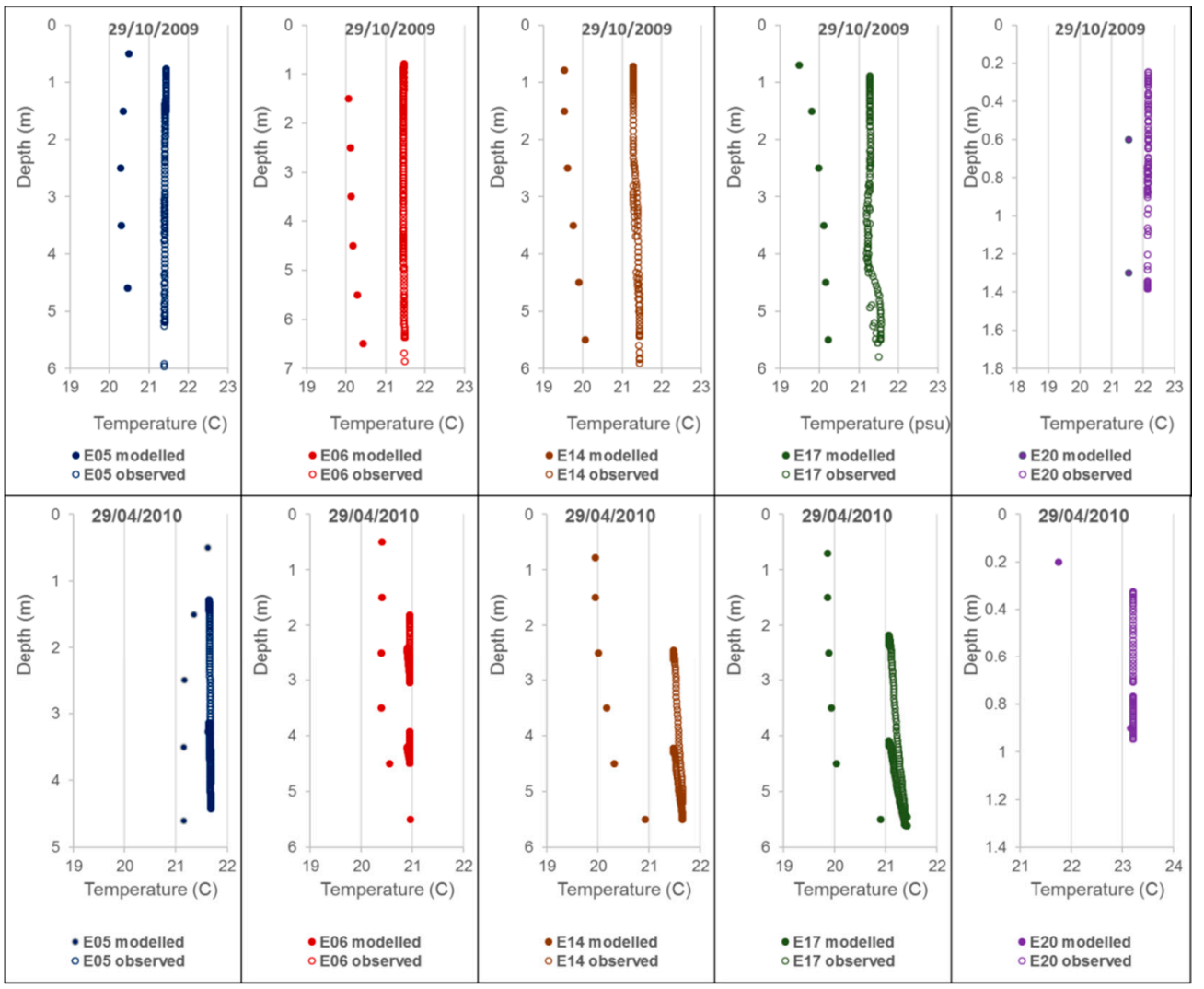

Figure 4. Modelled and observed vertical profiles of temperature on 29 October 2009 and 29 April 2010. 
The current patterns described by De Pascalis et al. [27], and reported in the study site description (Section 2.1), referred to a 2D simulation. The application of the SHYFEM model in its 3D formulation allowed for the description of the Mar Menor circulation patterns both at the surface and at the bottom. Figures S9 and S10 in Supplementary Materials show the general circulations in the lagoon under East and South West wind conditions. Regarding the circulation at the surface and bottom layers for Figures S9 and S10, it can be seen that the currents mostly followed the direction of the wind in the upper layer and the opposite direction in the bottom layer. On the other hand, the circulation for the depth averaged currents was similar to the one described in Section 2.1 for the 2D model. For the Eastern winds, there existed a counter-clockwise current in the Northern part of the lagoon and a clockwise current in the central and southern area, whereas for the South West winds, the most significant feature was the existence of a current flowing from North to South along the central part of the lagoon, as well as smaller circulations at both sides.

Regarding the tidal effects in the lagoon, time series of water levels and velocities were taken at the different stations considered for the validation of the model in order to compare them and analyse if there were changes in the tidal wave propagation. Figures 5 and 6 showed the aforementioned time-series for a period of five days, during which the flow inside the lagoon through the channels is maximum.

Regarding the water levels, although differences were only noticeable for the peak levels, it had to be taken into consideration that the stations are located in areas with different depths. Therefore, the friction component had more or less influence and it was difficult to determine the effects over the propagating tidal wave, although in the West-East direction, it could be observed that peak levels were higher towards La Manga, closer to the channels.

In terms of the current speed it seemed difficult to analyse them because the circulation in the lagoon is complex. It does not follow a bidirectional pattern, as in narrower bays or estuaries, which have a more linear morphology. In this sense, the phase shift of the currents is not clear.
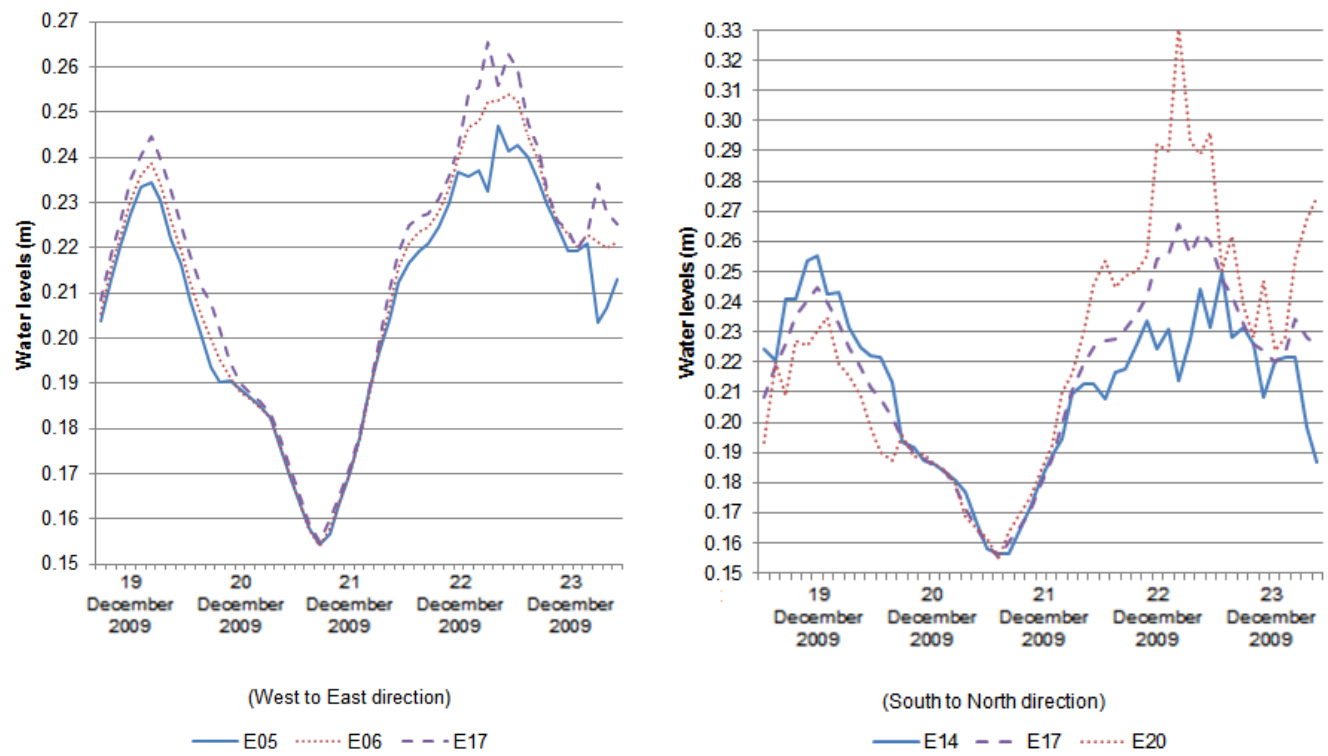

Figure 5. Time series of water levels at stations E05, E06, and E17 (left) and stations E14, E17, and E20 (right) from 19 December 2009 to 23 December 2009. 

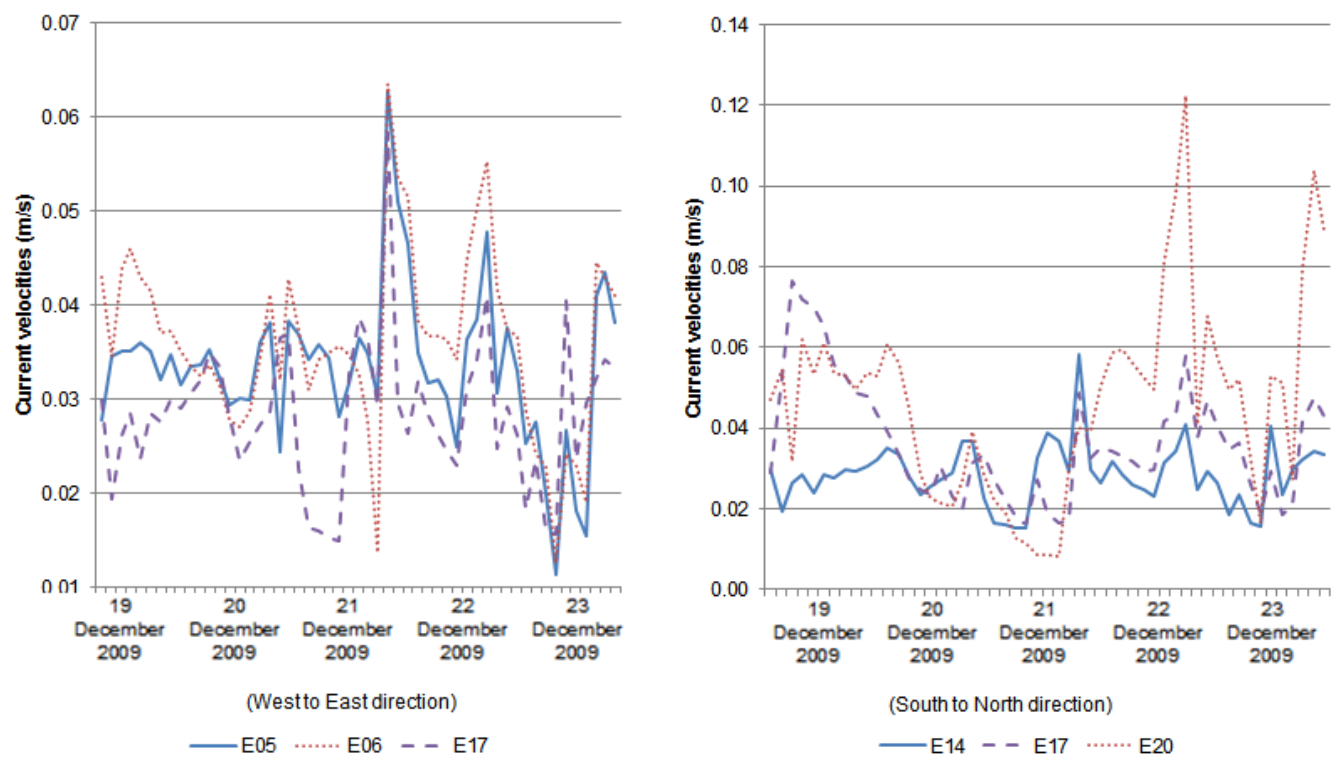

Figure 6. Time series of current speeds at stations E05, E06, and E17 (left) and stations E14, E17, and E20 (right) from 19 December 2009 to 23 December 2009.

This analysis demonstrated that tides are not the main forcing action in the lagoon system but wind is, as has been mentioned before.

\subsubsection{Dredging Scenarios}

In order to analyse the effect of dredging the Encañizadas (Enc) and Marchamalo (Mar) (Figure 1) channels on the lagoon regime and the potential environmental impacts, up to 10 new bathymetry scenarios were created. Both channels were considered for the dredging scenarios due to recent siltation problems. Dredging activities at El Estacio channel were not included because it is significantly deeper than the other channels and does not present such problems.

Figures 1 and 7 show the global bathymetry in the situation without dredging, i.e., the reference simulation, referred to in the following sections as "Undisturbed", and the local bathymetries at each channel for the individual dredging scenarios.

The different bathymetry scenarios covered several magnitudes of the dredging depths and extensions, ranging from smaller maintenance and partial dredging activities (abbreviated as 'Maint' and 'part' in the simulation names) to an increase in the average depth of $1 \mathrm{~m}$ distributed over the whole extension of the channels. The dredging actions had been analysed separately and in combination for both channels (Maint_Enc-Mar_0.5m, Enc_Mar_1m and Enc_Mar_1.5m).

In recent years, some issues have arisen for the fisheries and sailing activities at the Encañizadas and Marchamalo channels as a consequence of sediment deposition. Therefore, some scenarios have been proposed here in order to cover potential maintenance activities, such as the broadening of a sub-channel in Encañizadas (Maint_Enc) or the partial dredge of the outer Marchamalo channel (Mar_part_0.5m). For the other scenarios, covering more extensive dredging activities, a regularisation of the terrain uniformly over maximum depths of $0.5,1.0$, and $1.5 \mathrm{~m}$ has been considered, depending on the case.

For all simulations affecting the Encañizadas channel, the partially submerged sandbanks were lowered to the same level as in the rest of the channel, considering that they were initially located $0.2 \mathrm{~m}$ above sea level. 


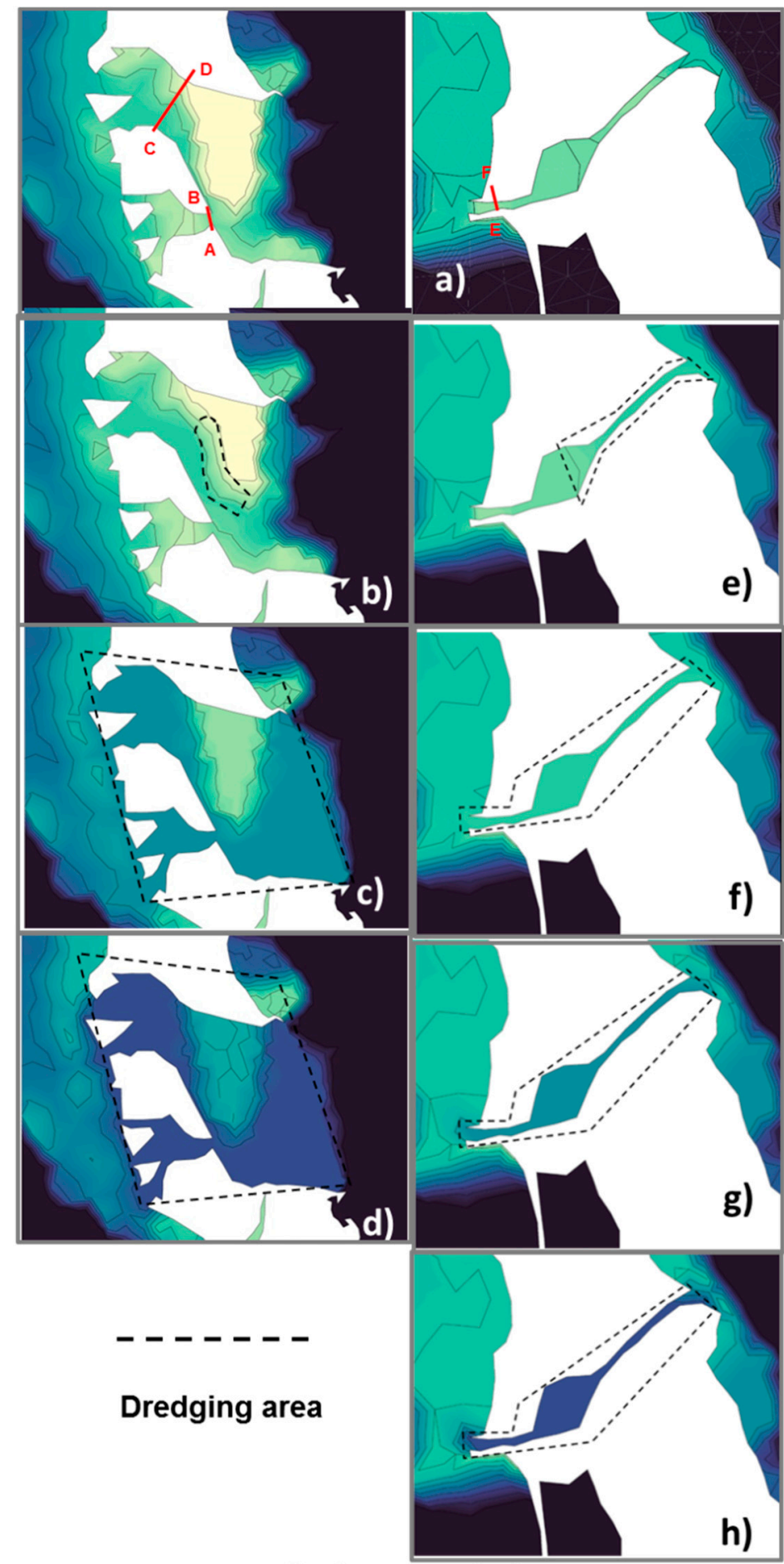

Bathymetry [m]

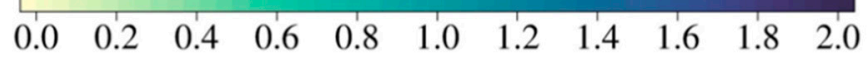

Figure 7. Bathymetry for dredging scenarios: (a) Undisturbed; (b) Maint_Enc; (c) Enc_1m; (d) Enc_1.5m; (e) Mar_part_0.5m; (f) Mar_0.5m; (g) Mar_1m; (h) Mar_1.5m.

Table 3 shows the maximum depths of the dredging activities for every scenario. The rest of the simulation parameters are the same as the ones presented in previous sections for the model in the Undisturbed scenario. 
Table 3. Average and maximum depths at the channels for each dredging scenario (yellow: individual dredging at Encañizadas/blue: individual dredging at Marchamalo/green: combined dredging at both channels).

\begin{tabular}{ccccccc}
\hline \multirow{2}{*}{ Scenario } & \multirow{2}{*}{ ID } & \multicolumn{2}{c}{ Depth Encañizadas $(\mathbf{m})$} & \multicolumn{2}{c}{ Depth Marchamalo $(\mathbf{m})$} & \multirow{2}{*}{ \% Section Change * } \\
\cline { 3 - 6 } & & Average & Maximum & Average & Maximum & \\
\hline Undisturbed & 1 & 1.06 & 3.10 & 0.39 & 0.60 & - \\
Maint_Enc & 2 & 1.09 & 3.10 & 0.39 & 0.60 & 0.0 \\
Enc_1m & 3 & 0.92 & 1.00 & 0.39 & 0.60 & 57.3 \\
Enc_1.5m & 4 & 1.42 & 1.50 & 0.39 & 0.60 & 106.1 \\
Mar_part_0.5m & 5 & 1.06 & 3.10 & 0.43 & 0.60 & 0.0 \\
Mar_0.5m & 6 & 1.06 & 3.10 & 0.50 & 0.50 & 1.0 \\
Mar_1m & 7 & 1.06 & 3.10 & 1.00 & 1.00 & 3.6 \\
Mar_1.5m & 8 & 1.06 & 3.10 & 1.50 & 1.50 & 6.2 \\
Maint_Enc-Mar_0.5m & 9 & 1.09 & 3.10 & 0.50 & 0.50 & 1.0 \\
Enc_Mar_1m & 10 & 0.92 & 1.00 & 1.00 & 1.00 & 61.0 \\
Enc_Mar_1.5m & 11 & 1.42 & 1.50 & 1.50 & 1.50 & 112.3 \\
\hline
\end{tabular}

* With respect to the Undisturbed case at cross sections A-B, C-D and E-F, shown in Figure 5a.

\section{Results}

\subsection{Current Speed}

An evaluation of the hydrodynamic changes in the current speed modules was performed by comparing the results from the simulations with and without dredging. Figure 8 presents the modules of the current velocity in the Undisturbed scenario averaged over the vertical dimension and over each season period. It can be seen that some areas around the coastline and the islands usually show higher values.

\section{Current Velocity [m/s]}

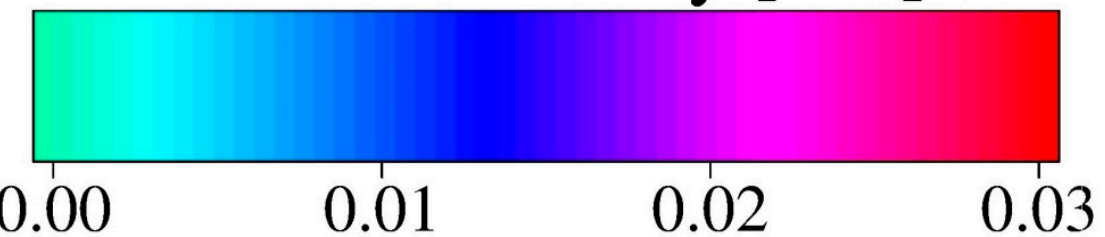

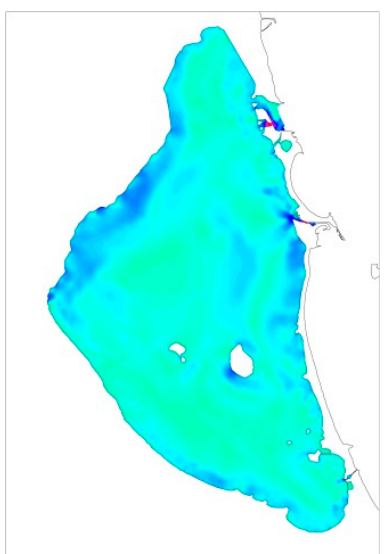

(a)

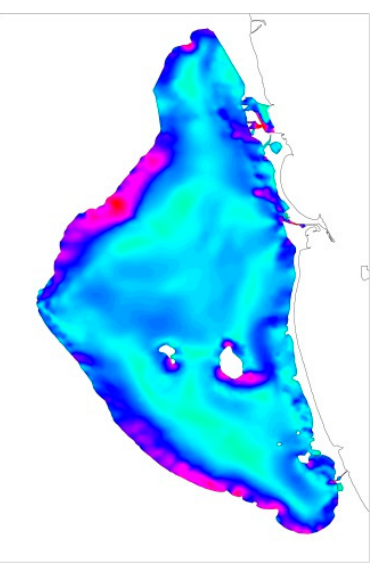

(b)

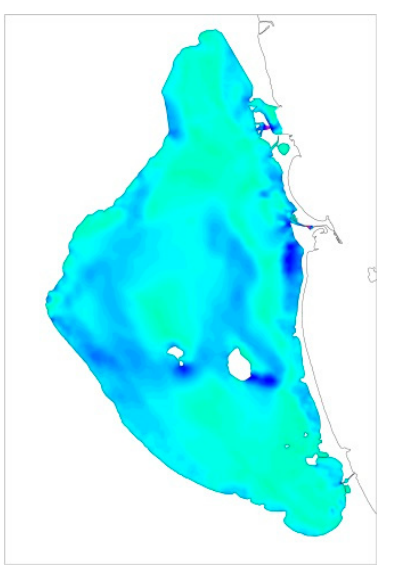

(c)

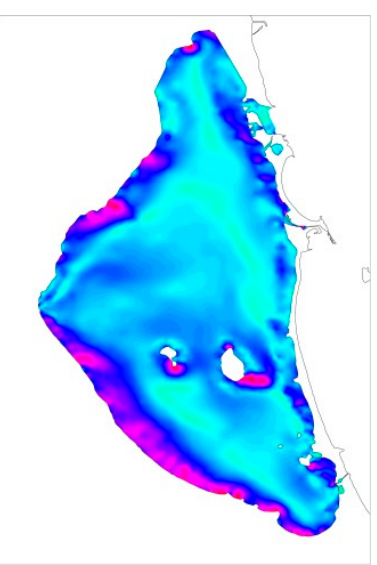

(d)

Figure 8. Seasonal average velocities. 
Figure 8 shows the differences between the vertically averaged current speed with and without dredging during the Spring, showing the effect of the shallower or less extensive dredging actions and the more severe ones, respectively. The Spring period has been chosen here to illustrate the changes as an example, given the fact that it is important for the reproduction and connectivity of some of the main fish species in the lagoon. In any case, the rest of the maps for each season can be found in the Supplementary Materials (Figures S1-S3).

From Figure 9 it was seen that the effect of dredging the channels was not negligible and that the current speed modules generally decreased with dredging up to a maximum value of $5 \mathrm{~mm} / \mathrm{s}$. Some of these reduced speeds are found in locations near the coastline.

In most of the dredging scenarios, the current speed modules were reduced in and around the areas where the dredging activity was carried out over the year. However, there was some kind of interaction with El Estacio channel, where an increase of the current speed appeared in most of the cases.

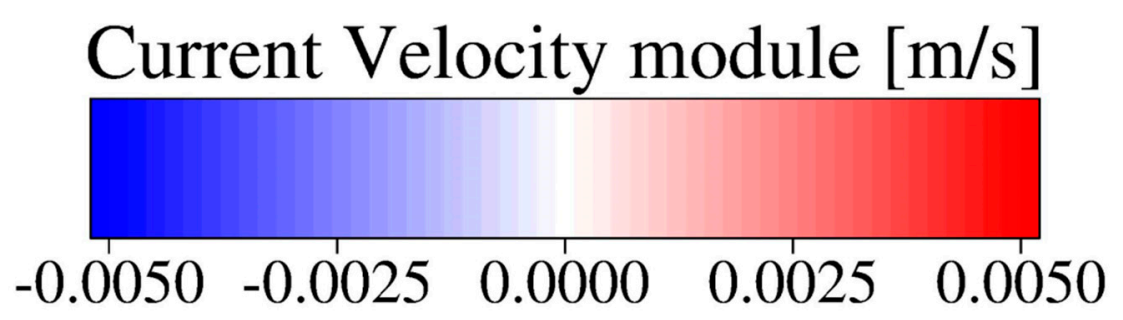

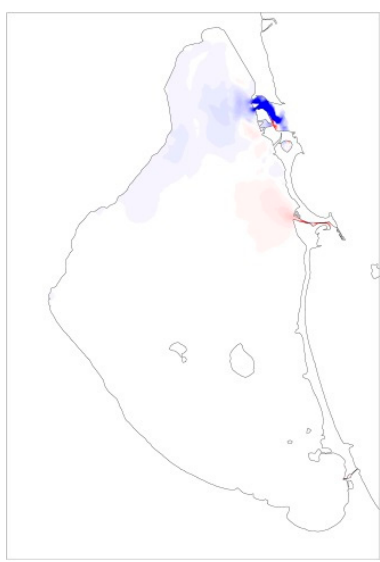

(a)

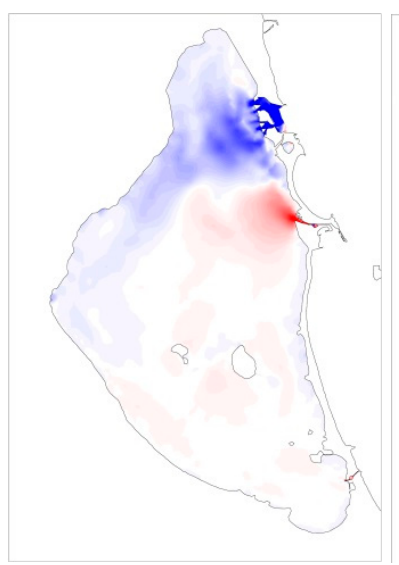

(e)

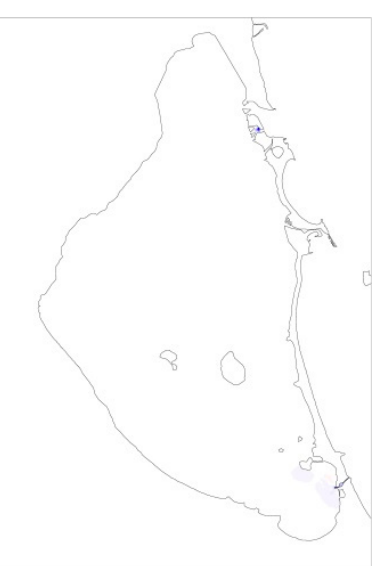

(b)

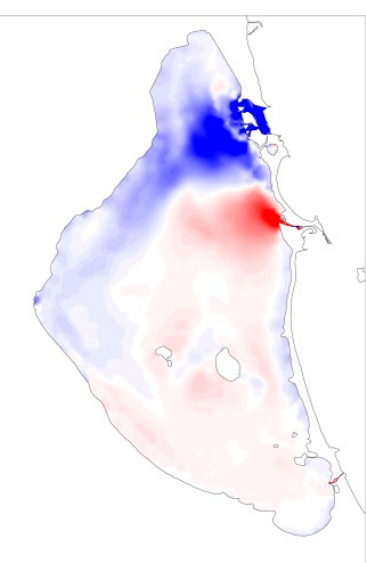

(f)

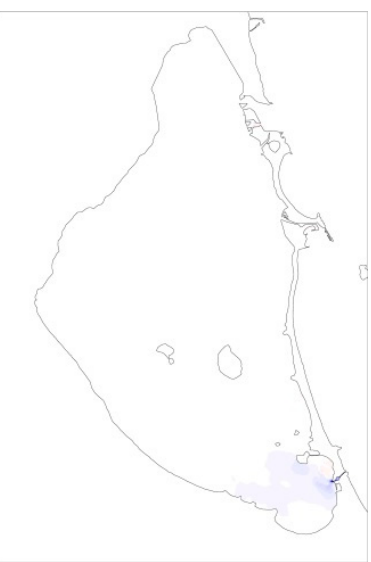

(c)

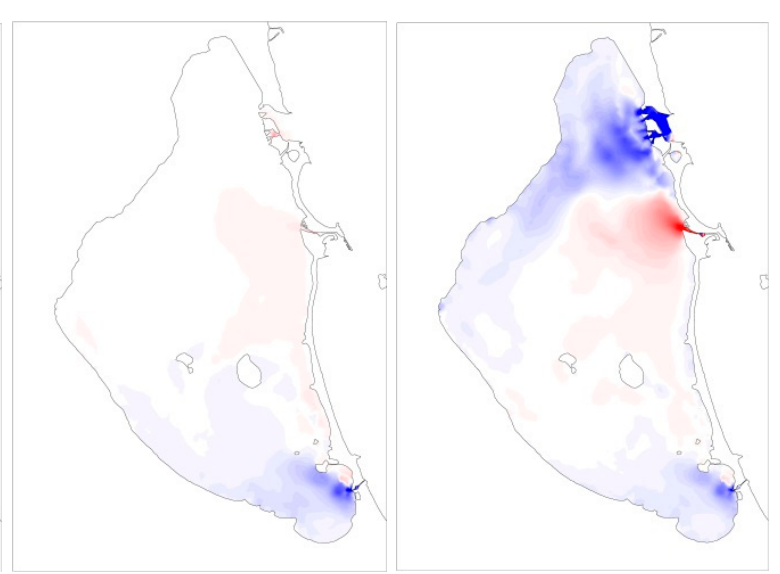

(g)

Figure 9. Cont. 


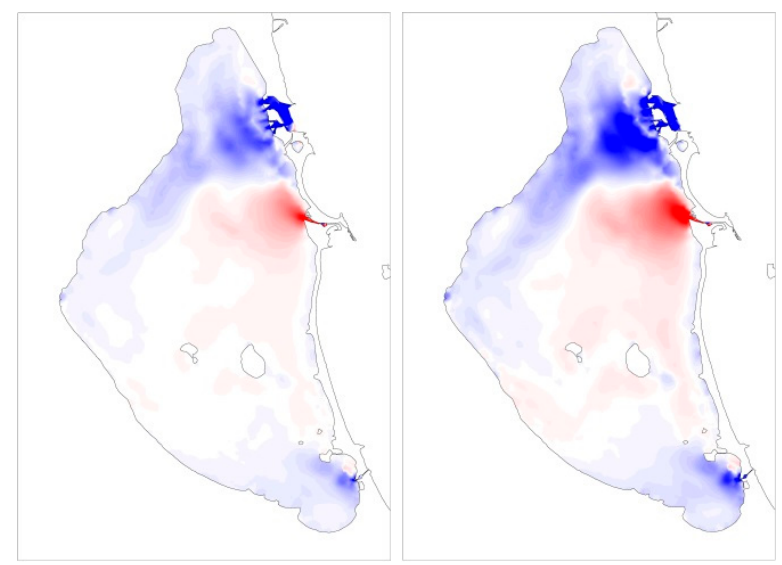

(i)

(j)

Figure 9. Current speed differences in spring: (a) Maint_Enc; (b) Mar_part_0.5m; (c) Mar_0.5m; (d) Maint_Enc_Mar_0.5m; (e) Enc_1m; (f) Enc_1.5m; (g) Mar_1m; (h) Mar_1.5m; (i) Enc_Mar_1m; (j) Enc_Mar_1.5m (Red: increase/Blue: decrease).

The spatial distribution of the changes over the current speed also varied with the season of the year. Regarding the currents directions, Figure S4 in the Supplementary Material shows the velocity field, averaged over the total depth, for the situations in which the discharges through El Estacio reach their maximum values in the directions towards the Mar Menor or the Mediterranean Sea on 13 February 2010 and 20 February 2010, respectively. From the global map in Figure S4a it can be seen that the global circulation pattern was characterised by an anti-cyclonic circulation in the uppermost part of the lagoon, a cyclonic circulation in the central part, and smaller structures in the South sub-basin moving in anti-clockwise direction around the islands and close to the shoreline. Figure S4b shows that the same circulations remained, but they followed the opposite directions. For both situations, the stronger currents were found in locations near the shoreline, the islands and within the channels. Similarities can be found between the cyclonic and anti-cyclonic circulations, and current structures from the results of the thesis by Pérez-Ruzafa [31] and López-Castejón [29]. López-Castejón [29] identified the North circulation as the most frequent circulation occurring in the lagoon due to one of the dominant winds. The existence of different circulations in the North and South sub-basins was also described in other works $[26,27,30]$.

The effects of the dredging activities were analysed for each scenario. For the shallower dredging scenarios, no significant effects were found in the global circulation patterns, but some changes in the currents intensity and direction through the channels were seen from Figures S5 to S8 in the Supplementary Material. Despite the distance between them, dredging an individual channel can affect the others.

For the deeper dredging activities, the changes in the global circulation were analysed in Figure 10. The dredging activities affecting the Marchamalo channel individually did not seem to have a significant influence on the rest of the lagoon circulation, whereas for those scenarios involving the dredging of Encañizadas channel, the effects were more significant. 


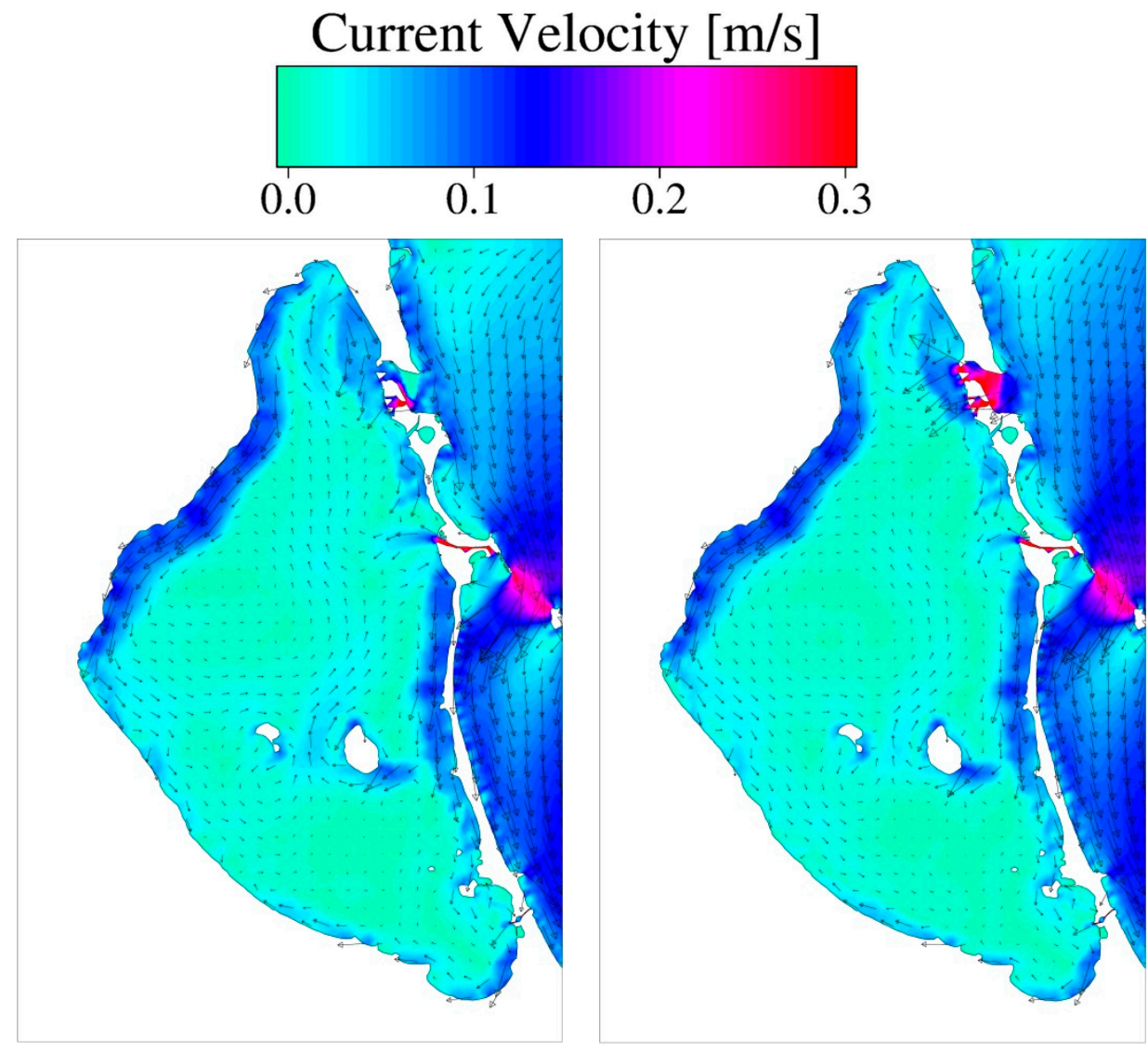

(a)

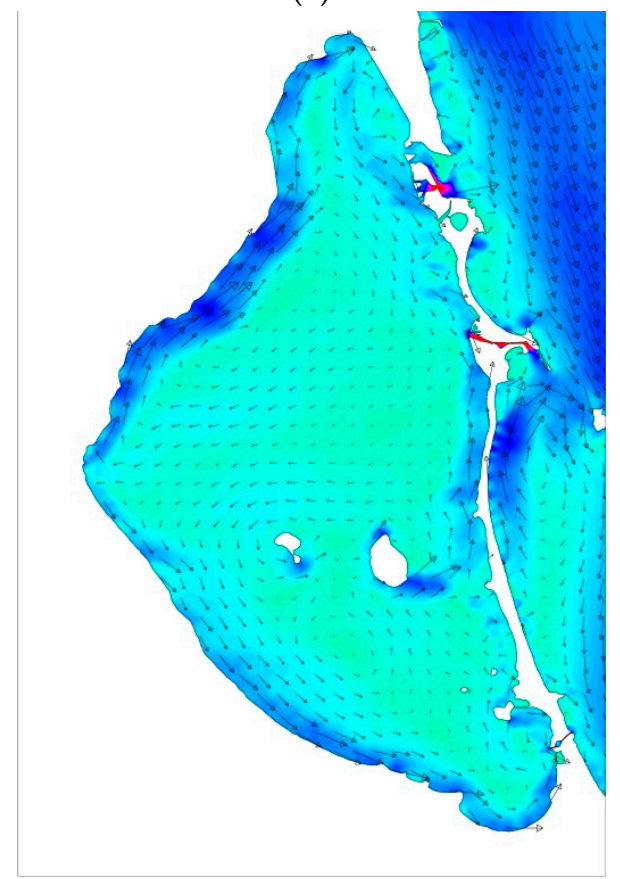

(c) (b)

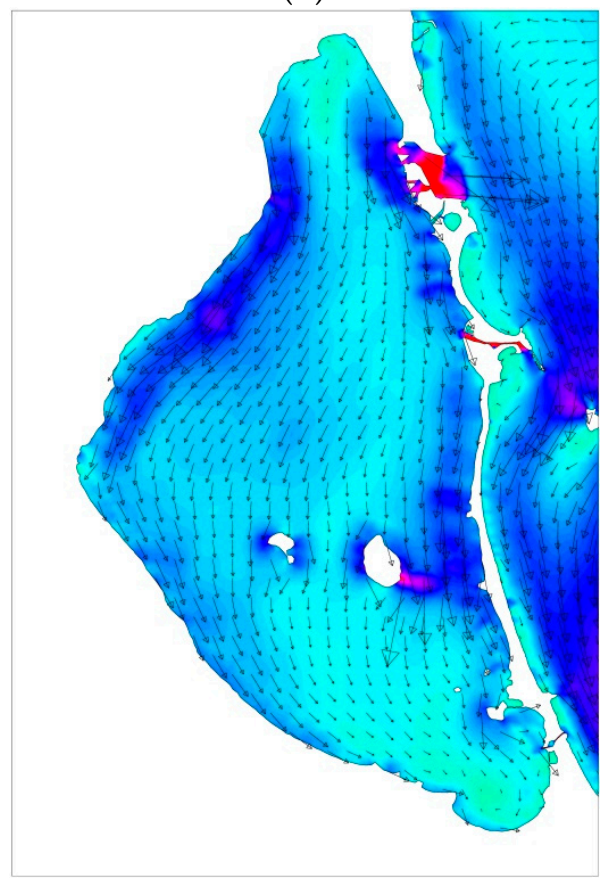

(d)

Figure 10. Vertically averaged current speeds at maximum discharge through El Estacio towards the lagoon (a) Undisturbed; (b) Enc_1m, and out of the lagoon: (c) Undisturbed, and towards the Mediterranean (d) Enc_1m. 
In Figure 10a,b, for scenario Enc_1m the high currents going out of El Estacio can affect the sub-gyre in the Northern part of the lagoon with respect to the Undisturbed scenario. However, from Figure 10c,d it was noted that the dredging of Encañizadas provoked a serious modification of the previously described circulation patterns during the maximum flow out of the lagoon through El Estacio, and the main gyres of the undisturbed condition would disappear.

Regarding the other scenarios, the standard deviation was calculated for the situation of the maximum flow through the channels into the lagoon in Table 4. It represented the variability of the velocity modules over the domain of the lagoon. From Table 4, it can be seen that the standard deviation was increased for the scenarios with larger dredging extensions and the combined cases.

Table 4. Standard deviation of the current velocity modules during the maximum flow through the channel into the lagoon.

\begin{tabular}{cc}
\hline Scenario & STDEV_curr $(\mathrm{m} / \mathbf{s})$ \\
\hline Undisturbed & 0.030 \\
Maint_Enc & 0.033 \\
Enc_1m & 0.041 \\
Enc_1.5m & 0.048 \\
Mar_part_0.5m & 0.031 \\
Mar_0.5m & 0.039 \\
Mar_1m & 0.041 \\
Mar_1.5m & 0.043 \\
Maint_Enc-Mar_0.5m & 0.034 \\
Enc_Mar_1m & 0.043 \\
Enc_Mar_1.5m & 0.050 \\
\hline
\end{tabular}

The dredging of Encañizadas channel up to a certain maximum depth can lead to a situation where this channel has a higher influence on the global lagoon dynamics than El Estacio, which is currently the main inlet in terms of exchange of water between the lagoon and the open sea. The position of the main inlet has an influence on water circulation, as demonstrated by Jeyar et al. [21] in their study about a relocation of the inlet in Nador lagoon.

Regarding the changes in the vertical dimension of the currents field due to the dredging scenarios, Figures 11 and 12 show the currents in the surface and bottom layers as well as the cross sections along the North-South and West-East directions under two different situations, Undisturbed, and the dredging of Encañizadas channel up to $1 \mathrm{~m}$ depth (the rest of the scenarios have not been depicted here because they show similar behaviors). The first situation was related to the maximum fluxes flowing into the lagoon through the channels, while the second situation represented the maximum wind conditions during the period of the simulation. The purpose of this analysis was to gain further insights about the intrinsic mechanisms of the water circulation inside the lagoon.

From Figure 11a,e, it can be seen that the surface currents at the Northern area were increased due to the dredging in Encañizadas inlet. Regarding the vertical structure of the currents, Figure 11c,g also showed differences in the Northern side, that is, in the Undisturbed case, there were three layers with different current directions, while in the Enc_1m case there existed mainly two layers over the same area. Nevertheless, from Figure 12 it can be seen that the internal circulation of the lagoon was similarly affected by the maximum wind conditions independently from the dredging scenarios, with two well-differentiated counter-current layers. 


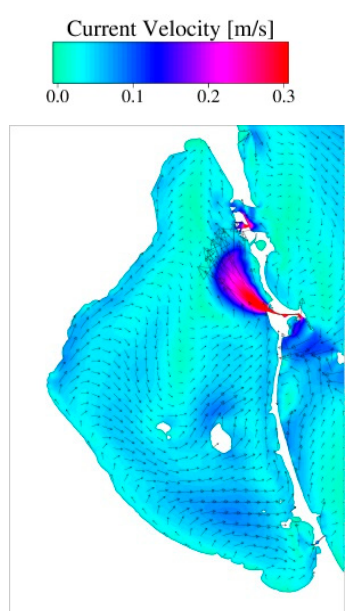

(a)

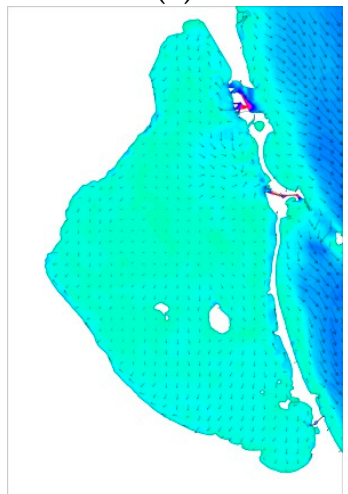

(b)

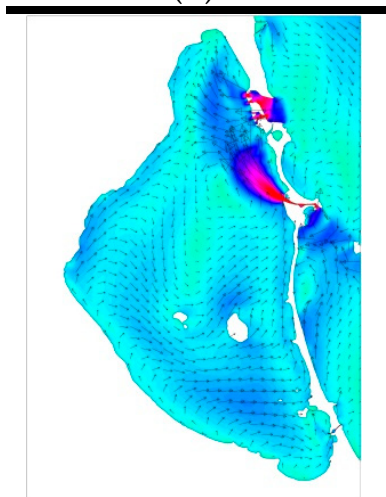

(e)

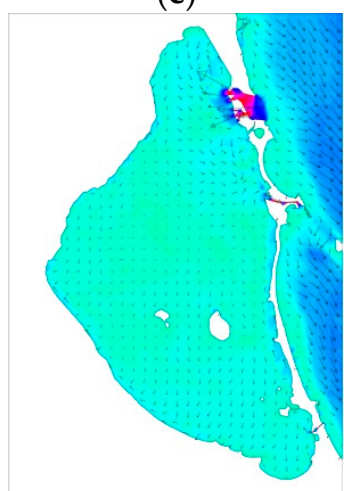

(f)

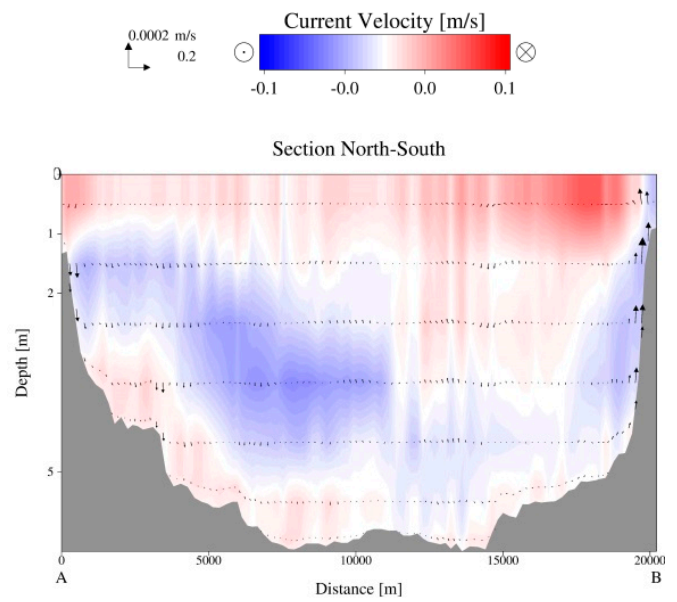

(c)

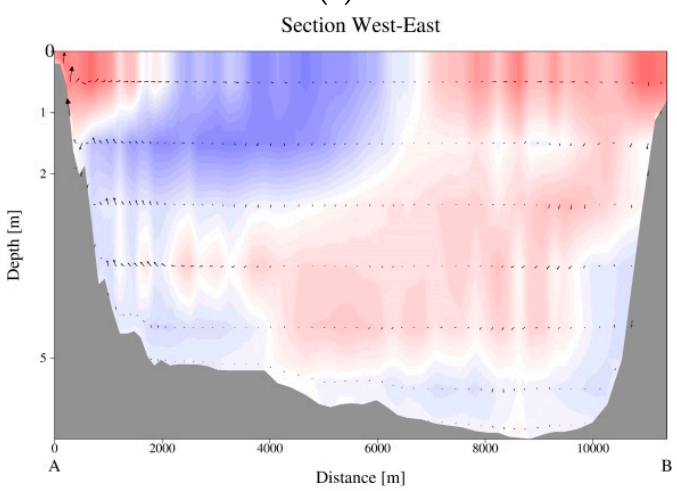

(d)

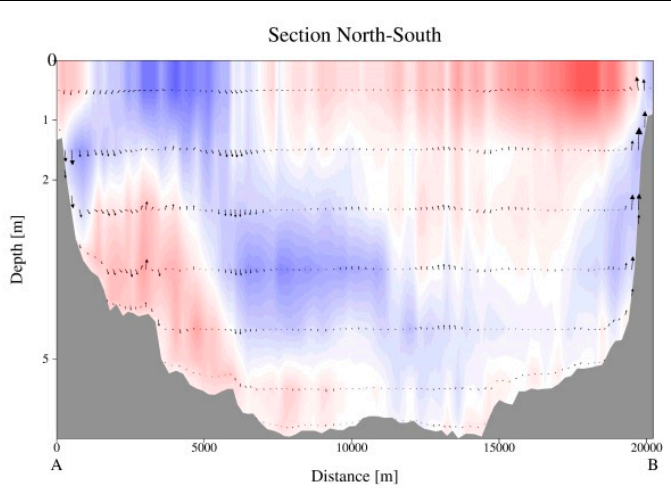

(g)

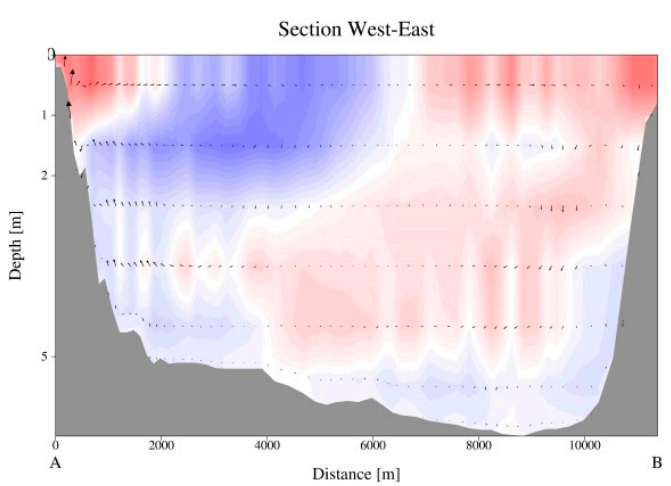

(h)

Figure 11. Current speeds at the Undisturbed (top) and Enc_1m (bottom) scenario on 21-12-2009 at $16 \mathrm{~h}$ (maximum flow inwards): surface $(\mathbf{a}, \mathbf{e})$ and bottom $(\mathbf{b}, \mathbf{f})$ layers/transects at North-South $(\mathbf{c}, \mathbf{g})$ and West-East (d,h) sections. (Red: outwards/Blue: inwards directions). 


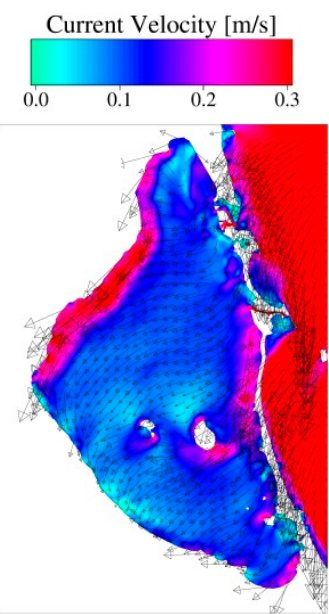

(a)

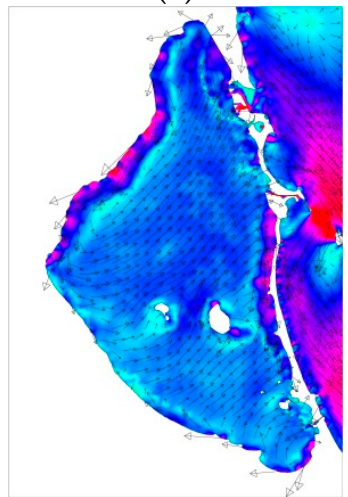

(b)

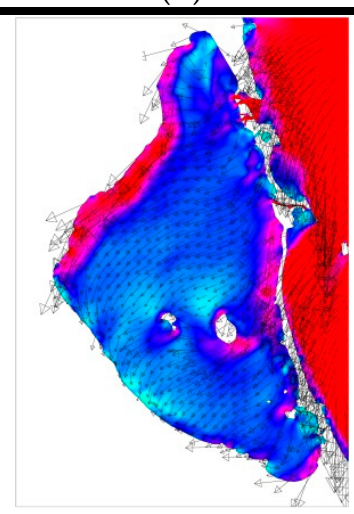

(e)

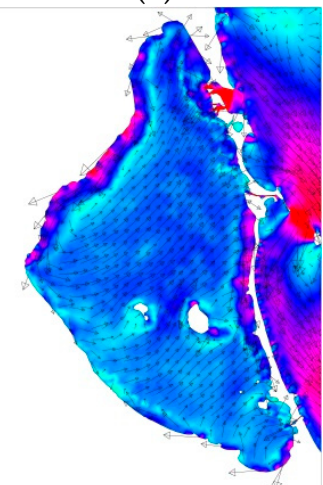

(f)

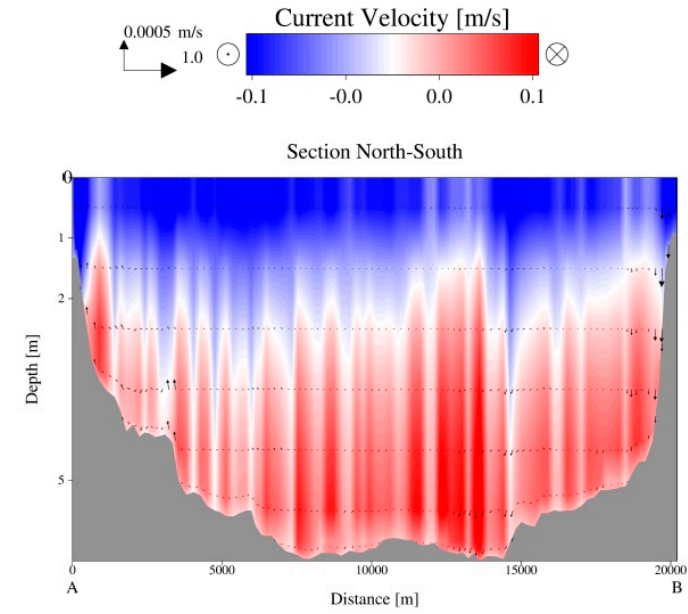

(c)

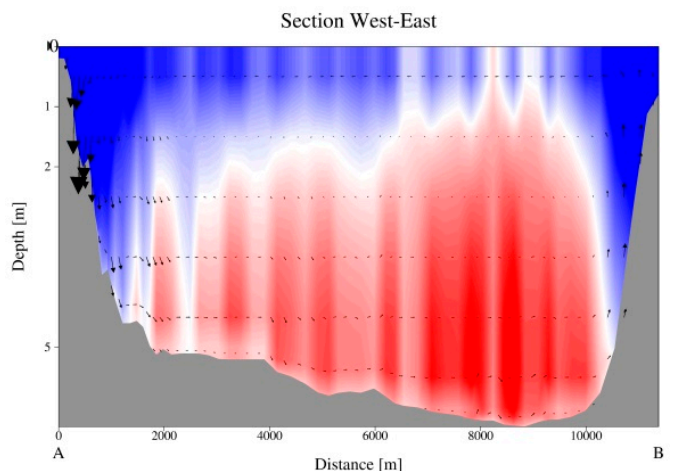

(d)

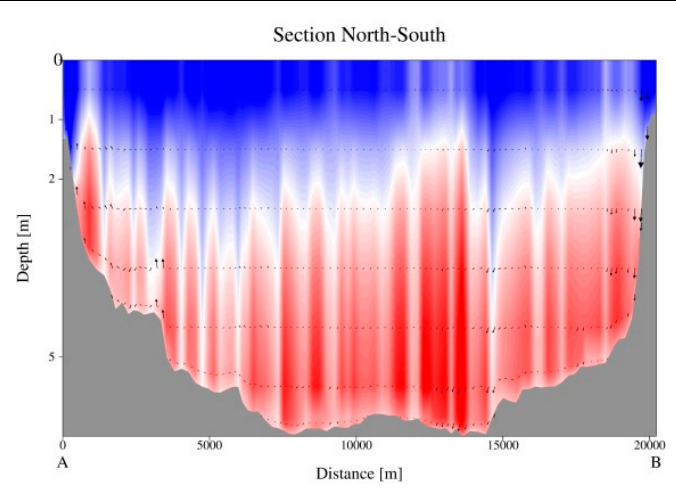

$(\mathrm{g})$

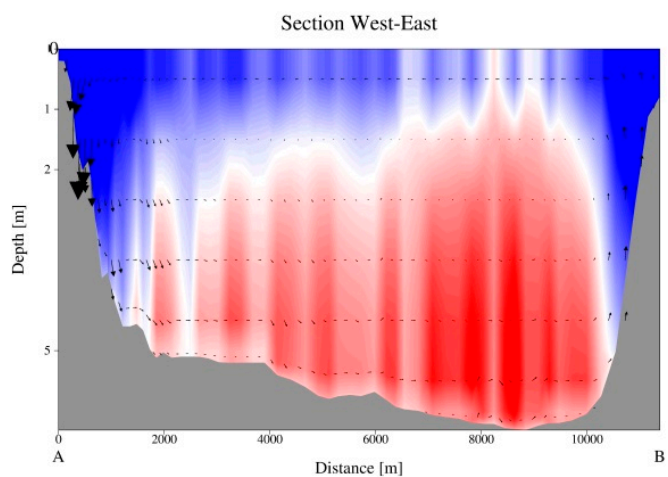

(h)

Figure 12. Current speeds for the Undisturbed (top) and the Enc_1m (bottom) scenario on 26 January 2010 at $10 \mathrm{~h}$ (maximum wind): velocities at the surface $(\mathbf{a}, \mathbf{e})$ and bottom $(\mathbf{b}, \mathbf{f})$ layers/transects at North-South $(\mathbf{c}, \mathbf{g})$ and West-East (d,h) sections. (Red: outwards/Blue: inwards directions). 


\subsection{Water Exchange-Discharges and Volumes through Channels}

The impact of the dredging activities on the water exchange through the channel inlets was also assessed. Table 5 shows the average discharge in and out of the lagoon through each channel and the total discharge as the sum of both channels during a one year period (1 April 2009--1 April 2010). The water fluxes through the channels are internally computed by the model as the discharges passing through the channels cross-sections closer to the lagoon. The average discharge in and out is calculated by separating the positive and negative hourly fluxes, respectively, given by the model over the considered period.

Table 5. Individual and total average discharge for the channel inlets (annual averages).

\begin{tabular}{|c|c|c|c|c|c|c|c|}
\hline \multirow{2}{*}{ Scenario } & \multirow{2}{*}{ ID } & \multirow{2}{*}{ Direction } & \multicolumn{3}{|c|}{ Average Discharge $\left(\mathrm{m}^{3} / \mathrm{s}\right)$} & \multirow{2}{*}{$\begin{array}{c}\text { Total Average } \\
\text { Discharge }\left(\mathrm{m}^{3} / \mathrm{s}\right)\end{array}$} & \multirow{2}{*}{$\underset{\substack{p_{\text {open }} \\
\left(\mathrm{m}^{2} / \mathrm{km}^{2}\right.}}{ }$} \\
\hline & & & Encañizadas & Estacio & Marchamalo & & \\
\hline \multirow{2}{*}{ Undisturbed } & \multirow{2}{*}{1} & In & 5.03 & 29.95 & 0.53 & 35.51 & \multirow{2}{*}{3.50} \\
\hline & & Out & 3.67 & 29.80 & 0.41 & 33.88 & \\
\hline \multirow{2}{*}{ Maint_Enc } & \multirow{2}{*}{2} & In & 9.19 & 29.17 & 0.52 & 38.88 & \multirow{2}{*}{3.72} \\
\hline & & Out & 6.93 & 29.89 & 0.41 & 37.23 & \\
\hline \multirow{2}{*}{ Enc_1m } & \multirow{2}{*}{3} & In & 31.54 & 26.49 & 0.46 & 58.49 & \multirow{2}{*}{5.51} \\
\hline & & Out & 26.72 & 29.63 & 0.42 & 56.77 & \\
\hline \multirow{2}{*}{ Enc_1.5m } & \multirow{2}{*}{4} & In & 67.58 & 24.67 & 0.42 & 92.67 & \multirow{2}{*}{7.22} \\
\hline & & Out & 62.40 & 28.04 & 0.40 & 90.84 & \\
\hline \multirow{2}{*}{ Mar_part_0.5m } & \multirow{2}{*}{5} & In & 5.02 & 29.92 & 0.71 & 35.65 & \multirow{2}{*}{3.50} \\
\hline & & Out & 3.66 & 29.79 & 0.57 & 34.02 & \\
\hline \multirow{2}{*}{ Mar_0.5m } & \multirow{2}{*}{6} & In & 5.02 & 29.90 & 0.93 & 35.85 & \multirow{2}{*}{3.54} \\
\hline & & Out & 3.67 & 29.77 & 0.78 & 34.22 & \\
\hline \multirow{2}{*}{ Mar_1m } & \multirow[b]{2}{*}{7} & In & 4.99 & 29.68 & 2.64 & 37.31 & \multirow{2}{*}{3.63} \\
\hline & & Out & 3.66 & 29.62 & 2.40 & 35.68 & \\
\hline \multirow{2}{*}{ Mar_1.5m } & \multirow{2}{*}{8} & In & 4.97 & 29.50 & 4.96 & 39.43 & \multirow{2}{*}{3.72} \\
\hline & & Out & 3.64 & 29.33 & 4.82 & 37.79 & \\
\hline \multirow{2}{*}{ Maint_Enc-Mar_0.5m } & \multirow[b]{2}{*}{9} & In & 9.18 & 29.13 & 0.90 & 39.21 & \multirow{2}{*}{3.54} \\
\hline & & Out & 6.93 & 29.85 & 0.78 & 37.56 & \\
\hline & & In & 31.43 & 26.41 & 2.35 & 60.19 & \\
\hline Enc_Mar_Im & 10 & Out & 26.60 & 29.43 & 2.42 & 58.45 & 5.63 \\
\hline Enc Mar $15 \mathrm{~m}$ & 11 & In & 67.28 & 24.55 & 4.11 & 95.94 & 7.43 \\
\hline Enc_MIar_t.Jmt & 11 & Out & 61.75 & 27.71 & 4.70 & 94.16 & 7.43 \\
\hline
\end{tabular}

The openness parameter, defined here as the sum of the channels cross-sections divided by the lagoon area, was also included in Table 5 because it gives an idea about the influence of the sea water exchange in the lagoon, according to Chubarenko et al. [46]. It was found that there was a high correlation $\left(R^{2}=0.98\right)$ between the openness parameter and the average discharges through the inlets in the inwards and outwards directions.

From Table 5 it can be seen that the total average discharge in the inwards direction of the channels was higher than the one in the direction going outside the channel. This phenomenon is due to the compensation of the high evaporation rates inside the lagoon. It can be noted that dredging the Encañizadas channel up to 1.0 and $1.5 \mathrm{~m}$ depth leads to a situation in which this channel becomes as influential as the El Estacio channel, with a similar or greater discharge, having important consequences for the global functioning of the lagoon. Table 6 shows the volume of water going in and out of the lagoon through each channel for each simulation scenario during the year. The last column represents the total volume, i.e., the sum of the channels volumes. The volumes were calculated as hourly fluxes from the model results, multiplied by $3600 \mathrm{~s}$ and summed along the one year period. 
Table 6. Individual volume in and out each channel and total volume exchanged during one year.

\begin{tabular}{|c|c|c|c|c|c|c|}
\hline \multirow{2}{*}{ Scenario } & \multirow{2}{*}{ ID } & \multirow{2}{*}{ Direction } & \multicolumn{3}{|c|}{ Annual Volume $\left(\mathrm{hm}^{3}\right)$} & \multirow{2}{*}{$\begin{array}{l}\text { Total Annual } \\
\text { Volume }\left(\mathrm{hm}^{3}\right)\end{array}$} \\
\hline & & & Encañizadas & Estacio & Marchamalo & \\
\hline \multirow{2}{*}{ Undisturbed } & \multirow{2}{*}{1} & In & 158.49 & 944.66 & 16.70 & 1119.85 \\
\hline & & Out & 115.62 & 939.77 & 12.95 & 1068.34 \\
\hline \multirow{2}{*}{ Maint_Enc } & \multirow{2}{*}{2} & In & 289.84 & 920.02 & 16.28 & 1226.14 \\
\hline & & Out & 218.43 & 942.67 & 13.04 & 1174.14 \\
\hline \multirow{2}{*}{ Enc_1m } & \multirow{2}{*}{3} & In & 994.81 & 835.53 & 14.65 & 1844.99 \\
\hline & & Out & 842.76 & 934.55 & 13.14 & 1790.45 \\
\hline \multirow{2}{*}{ Enc_1.5m } & \multirow{2}{*}{4} & In & 2131.48 & 777.96 & 13.25 & 2922.69 \\
\hline & & Out & 1968.11 & 884.45 & 12.77 & 2865.33 \\
\hline \multirow{2}{*}{ Mar_part_0.5m } & \multirow{2}{*}{5} & In & 158.39 & 943.72 & 22.27 & 1124.38 \\
\hline & & Out & 115.59 & 939.47 & 17.99 & 1073.05 \\
\hline \multirow{2}{*}{ Mar_0.5m } & \multirow{2}{*}{6} & In & 158.24 & 943.07 & 29.26 & 1130.57 \\
\hline & & Out & 115.65 & 938.83 & 24.61 & 1079.09 \\
\hline \multirow{2}{*}{ Mar_1m } & \multirow{2}{*}{7} & In & 157.45 & 936.15 & 83.33 & 1176.93 \\
\hline & & Out & 115.47 & 934.12 & 75.62 & 1125.21 \\
\hline \multirow{2}{*}{ Mar_1.5m } & \multirow{2}{*}{8} & In & 156.77 & 930.45 & 156.54 & 1243.76 \\
\hline & & Out & 114.92 & 925.09 & 151.99 & 1192.00 \\
\hline \multirow{2}{*}{ Maint_Enc-Mar_0.5m } & \multirow{2}{*}{9} & In & 289.58 & 918.75 & 28.51 & 1236.84 \\
\hline & & Out & 218.42 & 941.52 & 24.75 & 1184.69 \\
\hline \multirow{2}{*}{ Enc_Mar_1m } & \multirow{2}{*}{10} & In & 991.30 & 832.81 & 74.24 & 1898.35 \\
\hline & & Out & 838.89 & 928.34 & 76.23 & 1843.46 \\
\hline \multirow{2}{*}{ Enc_Mar_1.5m } & \multirow{2}{*}{11} & In & 2121.96 & 774.35 & 129.57 & 3025.88 \\
\hline & & Out & 1947.51 & 874.04 & 148.38 & 2969.93 \\
\hline
\end{tabular}

From Table 6 it can be seen that in the undisturbed case the volume entering the lagoon during one year higher than the volume going out of the lagoon. In the most severe dredging scenario (Enc_Mar_1.5m) the total volumes of water coming in and out of the lagoon were almost tripled with respect to the undisturbed case, and this would mean a change in the relevance of the inlets and in the role of connectivity. For the cases where the Encañizadas channel is dredged up to $1.0 \mathrm{~m}$ and $1.5 \mathrm{~m}$, the total volume through this channel became similar or higher than the volume through El Estacio, which represented the main inlet for the water exchange with the Mediterranean Sea for the rest of the cases.

For both the discharges and volumes, it was noted that the scenarios consisting of dredging activities at Encañizadas channel had a higher impact on El Estacio than the ones related to Marchamalo only, notably because the Encañizadas channel is wider and is also closer to the El Estacio channel.

These results give an idea about the complexity of the impacts of dredging on the water exchange and the interconnections between channels.

\subsection{Water Renewal Times and Salinity-Temperature Ranges}

Regarding the WRT, it was internally calculated by SHYFEM as the time during which the concentration of a tracer goes from an initial value of 1 to a value of zero. A more detailed description about the computation of the WRT in SHYFEM can be found in the works by Cucco \& Umgiesser [47] and Ferrarin et al. [18].

Figure 13 shows the WRT values, after averaging both between the vertical layers and horizontally between the elements forming the grid inside the lagoon. The standard deviations are represented in the error bars. 


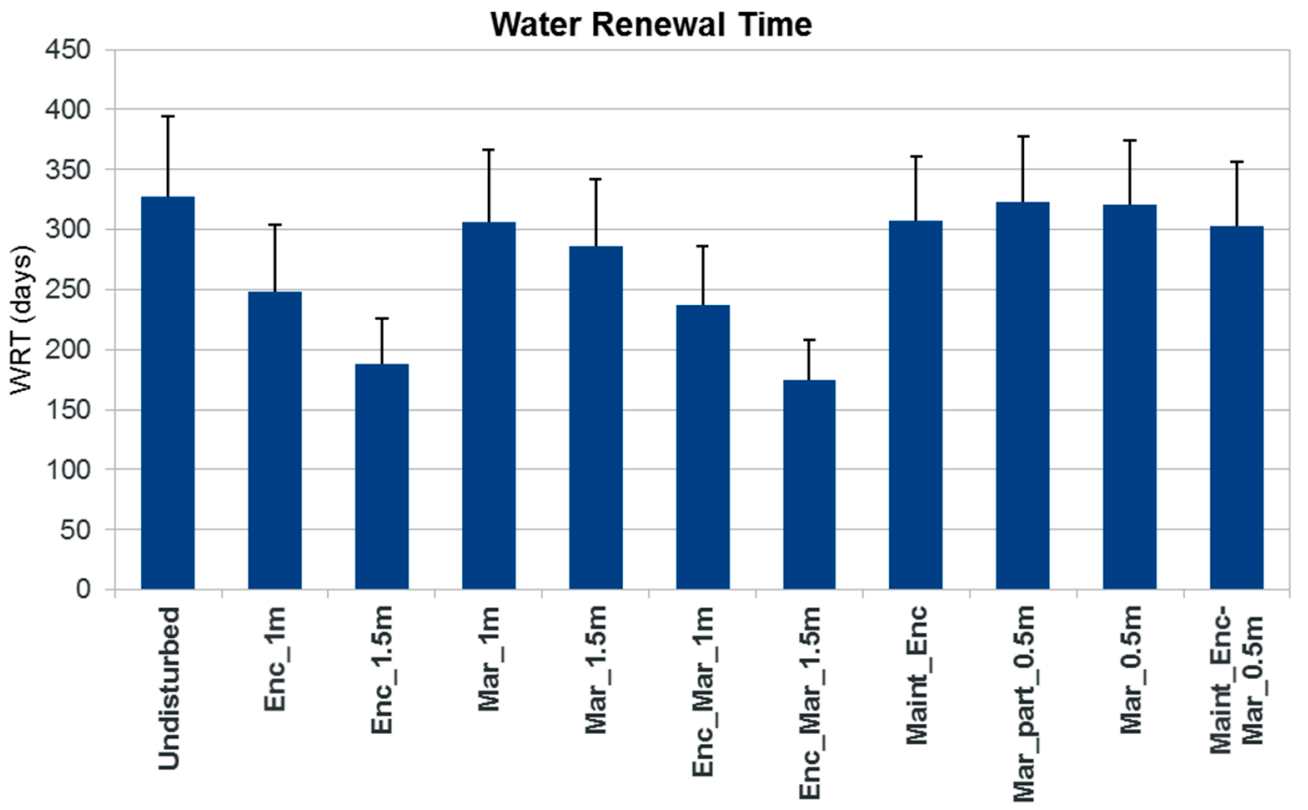

Figure 13. Average water renewal time (WRT) and STDEV of the WRT (black lines) in the Mar Menor lagoon for each simulation.

An important reduction of the average WRT can be observed and the values were almost halved for the combined dredging in both channels with the deepest scenario (Enc_Mar_1.5m).

Figure 14 shows the correlation between the openness parameter and the water renewal times. The good correlation $\left(R^{2}=0.97\right)$ suggested that the openness parameter could be regarded as a suitable indicator to characterise the water exchange and renewal times in this specific lagoon. The latter aspects were useful for clarifying the description of the biological features and the species richness.

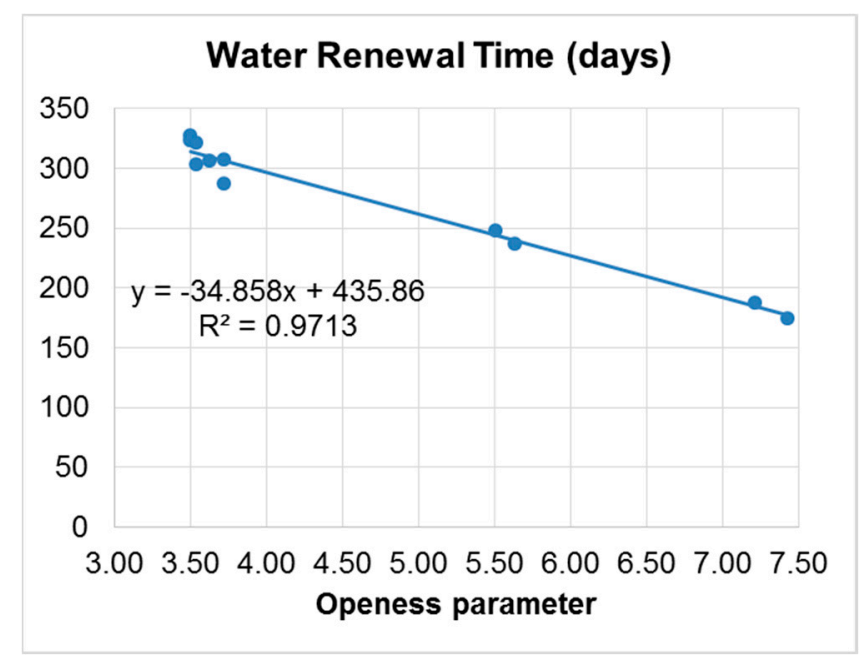

Figure 14. Relationship between the openness parameter and water renewal time.

Figure 15 shows the distribution of the vertically averaged WRT over the lagoon. It can be remarked that the values of the WRT were higher for the Southern area, maybe due to the reduced water exchange through Marchamalo channel, which, in addition, is located at a greater distance from the El Estacio channel. According to the study by Ghezzo et al. [10], El Estacio represents the main pathway of exchange of particles with the sea, with the Northern part appearing to exchange more particles with the sea than the others. 


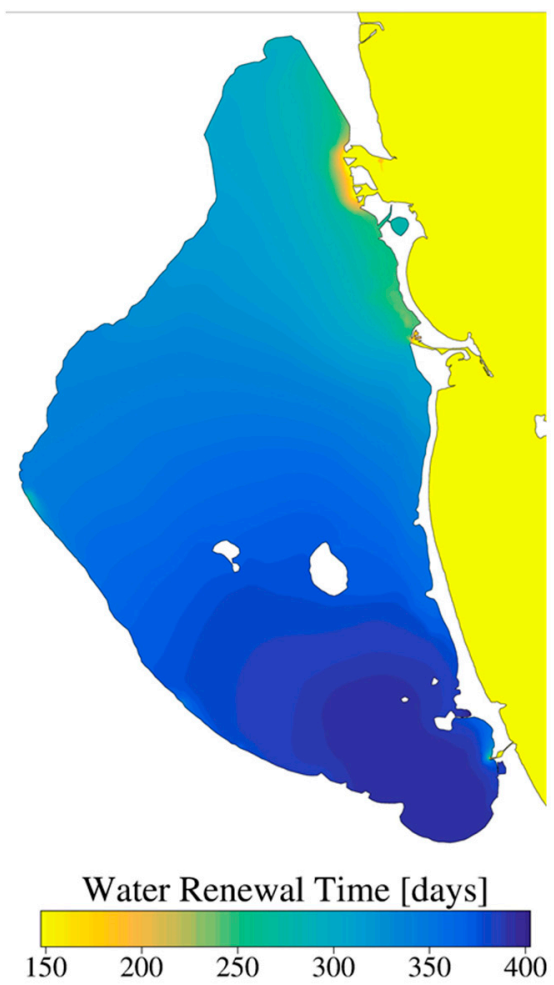

Figure 15. Vertically averaged water renewal time in the Undisturbed scenario.

The spatial distribution of the impacts from the dredging activities over the WRT was also analysed considering the differences between each scenario and the scenario "Undisturbed". These differences can be found in Figure 16, where negative values indicate a reduction of the WRT.

The first observation was that the WRT change was not spatially homogeneous. From Figure 16 it can be seen that the effect of dredging the Encañizadas channel on the WRT increased close to the inlets and decreased in the Southern part of the lagoon. For the dredging of Marchamalo channel, the impact was localised in the scenario Mar_1m, while extending over a broader region of the lagoon in the scenario Mar_1.5m. For the combined scenarios (Enc_Mar_1m and Enc_Mar_1.5m), the effects were stronger and covered the entire area of the lagoon, with higher impacts in locations near the channels and the Southern sub-basin.

The aforementioned effects have implications for the spatial structure of the WRT existing in the undisturbed case. A less heterogeneous distribution could appear in some of the scenarios, while other simulations kept higher WRT values in the Southern sub-basin, although their differences with the values in the Northern sub-basin were smaller than in the Undisturbed scenario.

In order to account for the spatial heterogeneity of the WRT values at each scenario, the standard deviation of the WRT over the lagoon domain was calculated, as shown in Figure 13. The results obtained through this method showed that the standard deviation was reduced for all of the dredging scenarios, and this reduction could reach up to 51\% for the combined scenario Enc_Mar_1.5m, which meant a significant homogenisation of the WRT over the lagoon. 
According to Ferrarin et al. [18], the WRT structure is also maintained by the internal circulation of the currents. For instance, they found in the case of morphological changes made in the Venice lagoon, that the spatial distribution of the WRT was more influenced by the current circulation than by water exchange with the open sea. The existence of this effect in the Mar Menor is suggested by the results obtained by Ghezzo et al. [10], which show that the stronger currents along the coastline may enhance the connection between locations in this area and that the connectivity between the lagoon and the sea is low compared to the connectivity between points within the lagoon.

Regarding the ecological implications of the WRT distribution, some ideas can be extracted from the study by Ferrarin et al. [37] for the Capo Perolo lagoons system, where the authors found that the confined areas show high chlorophyll concentration while the well mixed areas are more transparent and are in oligotrophic states. They also mention the existence of several communities associated with different habitats, some of them rich, in the shallow vegetated areas, and poor benthic communities in the deeper anoxic areas. Perez-Ruzafa et al. [8] analysed the dredging of sand close to the Encañizadas area, among other human activities in the area, and the impact on fish communities. As a consequence, those areas were occupied by the algae Caulerpa prolifera. Although abundance increased for some fish species, the diversity and richness of those ones in the dredging areas diminished.

The reduction in water renewal can be linked to changes in the annual variations of the physical properties of the lagoon. In order to provide an estimation of these changes, the monthly results of the salinity and temperature have been averaged over the lagoon domain and the maximum and minimum values have been calculated for a one-year period (from 1 April 2009 to 1 April 2010), as shown in Table 7.

Table 7. Maximum and minimum annual salinity and temperature values from monthly averages over the lagoon.

\begin{tabular}{ccccc}
\hline \multirow{2}{*}{ Scenario } & \multicolumn{2}{c}{ Salinity (PSU) } & \multicolumn{2}{c}{ Temperature $\left({ }^{\circ} \mathbf{C}\right)$} \\
\cline { 2 - 5 } & maximum & minimum & maximum & minimum \\
\hline Undisturbed & 43.64 & 39.37 & 28.33 & 9.03 \\
Maint_Enc & 43.65 & 39.33 & 28.34 & 9.06 \\
Enc_1m & 43.07 & 38.78 & 28.33 & 9.15 \\
Enc_1.5m & 42.25 & 38.16 & 28.30 & 9.24 \\
Mar_part_0.5m & 43.76 & 39.36 & 28.33 & 9.04 \\
Mar_0.5m & 43.77 & 39.36 & 28.33 & 9.04 \\
Mar_1m & 43.62 & 39.31 & 28.32 & 9.06 \\
Mar_1.5m & 43.46 & 39.19 & 28.31 & 9.09 \\
Maint_Enc-Mar_0.5m & 43.62 & 39.32 & 28.34 & 9.07 \\
Enc_Mar_1m & 42.93 & 38.67 & 28.32 & 9.18 \\
Enc_Mar_1.5m & 42.02 & 38.04 & 28.28 & 9.28 \\
\hline
\end{tabular}

Regarding the salinity, more significant decreases were noticed for the deeper and more extensive dredging scenarios, while for the temperature, changes were very slight and they mainly consisted of an attenuation (lower maximum and higher minimum values) for those scenarios with larger dredging interventions. Therefore, for the aforementioned cases, the dredging of the channels would lead to a Mediterraneisation of the water conditions of the Mar Menor. Further investigation are needed in order to evaluate their ecological implications in detail.

\section{Discussion}

The functioning of the coastal lagoons and their biological assemblages are strongly determined by the environmental conditions of each lagoon and by the connectivity that these environments maintain with the adjacent sea. Salinity has been considered as the key factor that governs both the physiology and ecology of the organisms inhabiting brackish water biotopes [48-52] and it is still considered among the most important factors [16]. At the same time, since the theory of confinement by Guelorget 
and Perthuisot [53], isolation with respect to the sea has been gaining relevance as a determining factor of the lagoon biology [54]. In recent years, the concept of the rate of renewal of oligoelements from marine sources in the original theory has been replaced by the rate of colonization of marine species, or biological connectivity [55-57]. In turn, both hydrological features and connectivity are conditioned by the lagoon geomorphology [58]. Therefore, any alteration of the channels of communication with the open sea can have important consequences in ecological integrity and the goods and services that the lagoons offer to human beings, such as fishing and quality of the water. In this paper, we have focused on the effects of dredging the inlets on lagoon hydrodynamics and we have not analyzed the associated changes in salinity and temperature or connectivity. Therefore, we will focus the discussion on the effect of the currents alteration on the lagoon biology, even though this is an aspect that has been scarcely investigated in the field of coastal lagoons.

\subsection{Impact of Deepening Channels on Beaches Quality}

The effect of dredging the channels is not negligible. The current speed modules are generally decreased. Some of these reduced speeds are found in locations near the coastline, with consequences for beach dynamics. Although current speeds are low inside the lagoon, being generally lower than $0.03 \mathrm{~m} / \mathrm{s}$, they govern important phenomena such as sediment and cell resuspension in the water column (grains of $\sim 1 \mathrm{~mm}$ diameter as estimated from Van Rijn [59]; Soulsby [60]), bottom and coastal erosion, and sand transport. From a biological point of view, they affect larval dispersal, connectivity among species populations, and food availability for filter feeders.

In the case of sediment transport, critical shear stress, entrainment modes, and settling velocity are determined by the size of the particle and current velocity [61]. Current velocities can decrease up to $-0.5 \mathrm{~cm} / \mathrm{s}$ or increase in other areas of the Mar Menor up to $+0.5 \mathrm{~cm} / \mathrm{s}$. According to the Hjulström curve, this range of variation will affect the transport/deposition equilibrium for sand particles between 0.35 and $0.6 \mathrm{~mm}$ [61] in beaches with stronger currents in summer and winter, and for particles between 0.03 and $0.15 \mathrm{~mm}$ in all the lagoons during spring and fall seasons. This may involve a higher rate of silting on most of the beaches at the internal coastline, especially in the North and South ends of the Mar Menor.

\subsection{Impact on Communities and Filter-Feeder Assemblages}

In the case of filter feeders, water currents not only affect the transport and availability of feeding particles, but also the anatomical and morphological adaptations of the species and individuals on the basis of Reynolds number restrictions [62,63]. The required equilibria between turbulence or inertial conditions and viscosity in the capture of food particles is determined by the combination between the current velocity and the length of the filtering and collecting structures. A reduction in the current velocity will not only mean a lower flow of food, but also maladjustment of the filtering structures to the new conditions. This can be especially important in typical filtering communities at the poorly illuminated areas of the pillars of the pontoons, where there is frequent settlement of sponges, cnidarians, bryozoans, polychaetes, cirripeds, and ascidians [31].

\subsection{Impact on Community Structure, Genetic Fluxes and Populations Connectivity}

Dredging of the channels, in addition to modifying the currents velocity, increases the rate of water renewal of the coastal lagoons. Both aspects are part of the processes that determine connectivity, both between the lagoon and the open sea, and within the lagoon itself $[10,11]$.

The configuration of the communities and the functioning of coastal lagoons ecosystems are largely governed by the degree of isolation and confinement $[53,54]$, that is, the restrictions imposed by the lagoon barriers to colonization rates of individuals and species. The openness parameter, which, as shown in this paper, is closely related to the WRT, is the main factor explaining species richness in coastal lagoons [58]. But, at the same time, the low colonization rates due to the restrictions imposed by the communication channels introduces a random component in the processes that leads 
to high spatio-temporal variability, preventing the system from becoming homogenized and from the exclusion of rare species by the dominant ones. This opens a wide range of possibilities for food webs structure and adaptations to change that are the basis of homeostatic mechanisms and complexity in some of the coastal lagoons [30,64].

In the Mar Menor lagoon, the previous dredging and widening of El Estacio inlet in the early 1970s increased water renewal rates, leading to a significant drop in salinity and smoothing extreme temperatures $[23,24]$. It allowed the colonisation and establishment of new marine species including the green algae Caulerpa prolifera, which expanded rapidly through the lagoon bottoms, producing a progressive increase in organic matter and anoxia in the sediments, with consequences for seagrass meadows and species of fishing interest, such as grey mullets [45]. As a part of the same process, other alien species, such as the jellyfish Cotylorhiza tuberculata and Rhizostoma pulmo, after a period of population growth, proliferated massively as a consequence of the changes in the trophic state of the lagoon, contributing to regulate the functioning of the trophic web and maintenance of water quality, but causing serious problems for tourist activity [26].

From the study by Pérez-Ruzafa et al. [24], it can be seen that the average reduction of the WRT values, from before dredging El Estacio (1970) to afterwards $(1980,1988)$ is approximately $37.5 \%$. Therefore, some of the scenarios (Enc_1.5m and Enc_Mar_1.5m) would have a significantly higher impact than the opening of El Estacio. An additional consequence is the loss of spatial structure of the WRT, with a decrease of the differences between sub-basins in the different simulations regarding the Undisturbed scenario.

Finally, it must be taken into account that WRT and the intensity of currents are two variables that contribute to connectivity but probably act through different mechanisms. Many species, both in their larval stages, as juveniles, and as adults, move or select their habitats depending on the intensity or proximity to coastal currents [65-67] Furthermore, fish optimise their swimming performance and swimming costs by taking advantage of the water currents [68]. In this way, currents contribute to determine habitat suitability and connectivity [68]. In a recent work, conducted in the Mar Menor, Perez-Ruzafa et al. [11] showed that Lagrangian connectivity is able to largely explain the genetic flows in populations of fish and invertebrates with pelagic larvae; however, not in the case of migratory species, such as Diplodus sargus, which colonizes the Mar Menor as a juvenile and uses currents to facilitate their displacements.

\subsection{Impact of Enlarging Channels on Fishing Activity}

It is necessary to highlight that these changes in currents intensity and WRT could significantly affect the fisheries inside the Mar Menor. The degree of communication between lagoons and the sea not only determines species diversity and the colonisation of marine species, but also fishing and biological productivity $[47,69,70]$. However, the effect of dredging coastal lagoon inlets on fishing production may vary considerably depending on the lagoon [3]. While in some lagoons, increasing the exchange with the sea can improve fisheries [71], in others it can lead to a drop in fishing yields [72,73].

Fishing yields in coastal lagoons are mainly related to the intensity of physicochemical gradients, increasing with the hydrographic differences with respect to the sea, the complexity of the lagoon perimeter, and shallowness $[3,47,74]$.

In the Mar Menor, an increase in the connection with the Mediterranean occurred over the last two centuries, either because of storms that broke the sandy bar which isolates the lagoon from the open sea, or because of successive dredging and creation of new inlets. This has translated into an important decrease in fishing yields, despite a significant increase in the number of species fished and in the contribution of Mediterranean species to the total catch $[23,24,73,75,76]$.

The final effect of dredging the inlets in coastal lagoons is probably the result of the balance between facilitating the colonization of species, and maintaining environmental gradients that favour energy flows and biological productivity. If the environmental conditions of the lagoon 
are homogenized and the differences with the open sea are reduced, biological production and fishing yields will decrease [3].

Furthermore, daily catches in gill nets are related with fish movements and the coastal fish take advantage of water currents in their daily movements that are activated by increasing water velocities and frontal periods [77-79].

\section{Final Remarks: Actions on the Inlets as a Management Tool}

From this study, it can be concluded that the impacts of dredging the channels on the hydrodynamics of a coastal lagoon increase with the magnitude of the dredging activities, that is, their maximum depth and extension. In this sense, there is a threshold for the magnitude of these activities beyond which important environmental effects can be expected.

Although the current speeds are small in the Mar Menor, which has been chosen as a representative case study, it can be remarked that the effects of dredging on the current modules are noticeable and could affect the sedimentation processes, as well as the sand and mud transport. The currents modules are generally decreased, particularly in the areas around the shoreline inside the Mar Menor, with consequences, not only for the communities of species living in those areas, but also for beach stability and dynamics. Besides this, dredging can affect the fish movements in the fishing areas. Unlike the rest of the lagoon, the velocity modules are increased in and around the area of El Estacio channel.

The spatial distribution of the effects of dredging over the velocity modules varies seasonally and the most severe dredging scenarios would lead to a change in the global circulation patterns inside the lagoon. The deeper dredging scenarios involving the Encañizadas channel show different behavior for the vertical stratification of the currents in the Northern area with respect to the Undisturbed state, except for the maximum wind conditions. Therefore, it is necessary to highlight that these changes can affect significantly the fishing yield in the Mar Menor, among other environmental factors.

The dredging of the channels also has an important effect on the maximum fluxes in and out the lagoon through the channels as well as the water exchange volumes with the Mediterranean Sea. This aspect has to be carefully taken into consideration in conjunction with the expected global warming effects on sea level rise.

Although the dredging scenarios based on partial maintenance or shallower depths show a reduction of the water renewal times closer to the usual ranges of variability of this factor in the lagoon, for the largest activities the reduction could reach half of the values of those of the undisturbed situation. This would have important consequences for the general regime of the lagoon and the species connectivity. Further study of this aspect will be carried out in the future.

Changes of the water renewal times spread over the whole lagoon in the case of dredging the Encañizadas channel whereas the effect is localised over the South sub-basin for those cases involving the Marchamalo channel only. The combination of dredging both channels, in general, leads to a homogenisation of the water renewal times along the lagoon, in contrast with the undisturbed situation, where the difference between the water renewal in the North and South is noticeable. This homogenisation could affect species biodiversity.

As a general remark, it can be said that maintenance of the exchange between coastal lagoons and the sea through inlets is a frequent management action [80], and is considered important for the biological functioning of a lagoon [81], avoiding dystrophic crises [82], and facilitating the migration of target fishing species [3]. However, the effects of dredging or building new communication channels may vary considerably from one lagoon to the other, and the ways in which inlets are managed must be carefully analysed [3].

Depending on the initial geomorphological and hydrodynamic conditions, dredging the channels can in some cases avoids excessive isolation of the lagoon, facilitating an active gradient in the physical conditions of the lagoon, as well as fish migration, and improvement of fisheries, whereas in other 
cases it can excessively increase communication with the sea, homogenizing the system and reducing the intensity of gradients, leading to a fall in fishing yields.

These practices, whether or not linked to fishing activity, can also lead to significant changes in the environmental conditions, the introduction of new species, lagoon biological productivity, the distribution of benthic macrophytes, and spatio-temporal heterogeneity in hydrological and environmental conditions, having strong consequences on lagoon communities and homeostatic capabilities $[9,24,30,56,58,64,83]$.

Therefore, these complex effects of modifying the geomorphology of the inlets on the general biodiversity and structure of lagoon communities should be taken into account in any restoration or integrated management plan for these ecosystems.

This study demonstrates that numerical models provide a suitable tool for evaluating the effects of human interventions on the sensitive environments of the coastal lagoons, as they can integrate all the different physical parameters involved in the regime of these systems in an accurate way. Predictive models of this kind will be essential for coastal lagoon management under the pressures of climate change. The analyses included in this research, some of which have been treated in an unprecedented way for the Mar Menor lagoon, can be applied generically to other locations.

Supplementary Materials: The following are available online at http:/ / www.mdpi.com/2073-4441/10/7/959/s1, Figure S1: Current speed differences in summer, Figure S2: Current speed differences in fall, Figure S3: Current speed differences in winter, Figure S4: Vertically averaged current speeds, Figure S5: Vertically averaged current speeds in Encañizadas at maximum discharge into the lagoon through El Estacio, Figure S6: Vertically averaged current speeds in Marchamalo at maximum discharge into the lagoon through El Estacio, Figure S7: Vertically averaged current speeds in Encañizadas at maximum discharge out of the lagoon through El Estacio, Figure S8: Vertically averaged current speeds in Marchamalo at maximum discharge out of the lagoon through El Estacio, Figure S9: Current velocity field for winds from the eastern direction, Figure S10: Current velocity field for winds for the southwestern direction.

Author Contributions: Á.P.-R. designed the study. M.G.-O. developed the numerical model and analysed the results with support from W.M., M.G. and F.D.P. G.U., C.M. and Á.P.-R. supervised the study and discussed the results in the context of the M.M., ecological processes and other lagoons functioning. M.G.-O. primarily wrote this manuscript with revisions and contributions from the other authors.

Funding: This work has been funded by the Spanish Ministry of Economy and Competitiveness project ConnectMar CTM 2014-56458-R.

Acknowledgments: We acknowledge the Agencia Española de Meteorología (AEMet) and Organismo Público Puertos del Estado for the meteorological and hydrographical data provided, respectively.

Conflicts of Interest: The authors declare no conflict of interest.

\section{References}

1. Pérez-Ruzafa, A.; Marcos, C.; Pérez-Ruzafa, I.M. Mediterranean coastal lagoons in an ecosystem and aquatic resources management context. Phys. Chem. Earth 2011, 36, 160-166. [CrossRef]

2. Newton, A.; Icely, J.; Cristina, S.; Brito, A.; Cardoso, A.C.; Colijn, F.; Ivanova, K. An overview of ecological status, vulnerability and future perspectives of European large shallow, semi-enclosed coastal systems, lagoons and transitional waters. Estuar. Coast. Shelf Sci. 2014, 140, 95-122. [CrossRef]

3. Pérez-Ruzafa, A.; Marcos, C. Fisheries in coastal lagoons: An assumed but poorly researched aspect of the ecology and functioning of coastal lagoons. Estuar. Coast. Shelf Sci. 2012, 110, 15-31. [CrossRef]

4. Patrolia, E.; Thompson, R.; Dalton, T.; Hoagland, P. The influence of weather on the recreational uses of coastal lagoons in Rhode Island, USA. Mar. Policy 2017, 83, 252-258. [CrossRef]

5. García-Ayllón, S. Integrated management in coastal lagoons of highly complexity environments: Resilience comparative analysis for three case-studies. Ocean Coast. Manag. 2017, 143, 16-25. [CrossRef]

6. Rebelo, C.F.C.; Alves, C.P.F.; Moiteiro, G.C.; Ezequiel, G.M.G.; Brasão, I.P.C.; De Vasconcelos, J.V.; De Jesus Carvalho, M.J.P. Tourism Through the Gaze of Stakeholders: The Case of Óbidos Lagoon in Portugal. Tour. Plan. Dev. 2015, 12, 447-462. [CrossRef]

7. Rova, S.; Pranovi, F.; Müller, F. Provision of ecosystem services in the lagoon of Venice (Italy): An initial spatial assessment. Ecohydrol. Hydrobiol. 2015, 15, 13-25. [CrossRef] 
8. Pérez-Ruzafa, A.; García-Charton, J.A.; Barcala, E.; Marcos, C. Changes in benthic fish assemblages as a consequence of coastal works in a coastal lagoon: The Mar Menor (Spain, Western Mediterranean). Mar. Pollut. Bull. 2006, 53, 107-120. [CrossRef] [PubMed]

9. Gamito, S.; Gilabert, S.; Marcos, C.; Pérez-Ruzafa, A. Effects of Changing Environmental Conditions on Lagoon Ecology. In Coastal Lagoons: Ecosystem Processes and Modeling for Sustainable Use and Development; Gönenç, I.E., Wolflin, J.P., Eds.; CRC Press: Boca Ratón, FL, USA, 2005; pp. 193-229.

10. Ghezzo, M.; De Pascalis, F.; Umgiesser, G.; Zemlys, P.; Sigovini, M.; Marcos, C.; Pérez-Ruzafa, A. Connectivity in Three European Coastal Lagoons. Estuar. Coasts 2015, 38, 1764-1781. [CrossRef]

11. Pérez-Ruzafa, A.; De Pascalis, F.; Ghezzo, M.; Quispe-Becerra, J.I.; Hernández-García, R.; Muñoz, I.; Marcos, C. Connectivity between coastal lagoons and sea: Asymmetrical effects on assemblages' and populations' structure. Estuar. Coast. Shelf Sci. 2018. [CrossRef]

12. Wu, Y.; Chaffey, J.; Greenberg, D.A.; Colbo, K.; Smith, P.C. Tidally-induced sediment transport patterns in the upper Bay of Fundy: A numerical study. Cont. Shelf Res. 2011, 31, 2041-2053. [CrossRef]

13. Davidson-Arnott, R.G.; Van Proosdij, D.; Ollerhead, J.; Schostak, L. Hydrodynamics and sedimentation in salt marshes: Examples from a macrotidal marsh, Bay of Fundy. Geomorphology 2002, 48, 209-231. [CrossRef]

14. Suanez, S.; Bruzzi, C. Shoreline management and its implications for coastal processes in the eastern part of the Rhône delta. J. Coast. Conserv. 1999, 5, 1-12. [CrossRef]

15. Grifoll, M.; Del Campo, A.; Espino, M.; Mader, J.; González, M.; Borja, Á. Water renewal and risk assessment of water pollution in semi-enclosed domains: Application to Bilbao Harbour (Bay of Biscay). J. Mar. Syst. 2013, 109, S241-S251. [CrossRef]

16. Pérez-Ruzafa, A.; Marcos, C.; Pérez-Ruzafa, I.M.; Pérez-Marcos, M. Coastal lagoons: "transitional ecosystems" between transitional and coastal waters. J. Coast. Conserv. 2011, 15, 369-392. [CrossRef]

17. Umgiesser, G.; Ferrarin, C.; Cucco, A.; De Pascalis, F.; Bellafiore, D.; Ghezzo, M.; Bajo, M. Comparative hydrodynamics of 10 Mediterranean lagoons by means of numerical modeling. J. Geophys. Res. Oceans 2014, 119, 2212-2226. [CrossRef]

18. Ferrarin, C.; Ghezzo, M.; Umgiesser, G.; Tagliapietra, D.; Camatti, E.; Zaggia, L.; Sarretta, A. Assessing hydrological effects of human interventions on coastal systems: Numerical applications to the Venice Lagoon. Hydrol. Earth Syst. Sci. 2013, 17, 1733-1748. [CrossRef]

19. Umgiesser, G.; Zemlys, P.; Erturk, A.; Razinkova-Baziukas, A.; Mèžinè, J.; Ferrarin, C. Seasonal renewal time variability in the Curonian Lagoon caused by atmospheric and hydrographical forcing. Ocean Sci. 2016, 12, 391-402. [CrossRef]

20. Malhadas, M.S.; Silva, A.; Leitão, P.C.; Neves, R. Effect of the bathymetric changes on the hydrodynamic and residence time in Óbidos Lagoon (Portugal). J. Coast. Res. 2009, Special Issue No. 56. 549-553.

21. Jeyar, M.; Chaabelasri, E.; Salhi, N. Numerical investigation of new alternative Nador lagoon inlet relocation. Int. J. Fluid Mech. Res. 2015, 42, 449-462. [CrossRef]

22. Teatini, P.; Isotton, G.; Nardean, S.; Ferronato, M.; Mazzia, A.; Da Lio, C.; Cellone, F. Hydrogeological effects of dredging navigable canals through lagoon shallows. A case study in Venice. Hydrol. Earth Syst. Sci. 2017, 21, 5627-5646. [CrossRef]

23. Pérez-Ruzafa, A.; Marcos, C.; Pérez-Ruzafa, I.M.; Ros, J.D. Evolución de las características ambientales y de los poblamientos del Mar Menor (Murcia, SE de España). Anales de Biología 1987, 53-65.

24. Pérez-Ruzafa, A.; Marcos-Diego, C.; Ros, J.D. Environmental and biological changes related to recent human activities in the Mar Menor (SE of Spain). Mar. Pollut. Bull. 1991, 23, 747-751. [CrossRef]

25. Pérez-Ruzafa, A.; Marcos, C.; Gilabert, J. The ecology of the Mar Menor coastal lagoon: A fast-changing ecosystem under human pressure. In Coastal Lagoons: Ecosystem Processes and Modeling for Sustainable Use and Development; Gönenç, I.E., Wolflin, J.P., Eds.; CRC Press: Boca Ratón, FL, USA, 2005; pp. 392-422.

26. Pérez-Ruzafa, A.; Gilabert, J.; Gutiérrez, J.M.; Fernández, A.I.; Marcos, C.; Sabah, S. Evidence of a planktonic food web response to changes in nutrient input dynamics in the Mar Menor coastal lagoon, Spain. Hydrobiologia 2002, 475/476, 359-369. [CrossRef]

27. De Pascalis, F.; Pérez-Ruzafa, A.; Gilabert, J.; Marcos, C.; Umgiesser, G. Climate change response of the Mar Menor coastal lagoon (Spain) using a hydrodynamic finite element model. Estuar. Coast. Shelf Sci. 2012, 114, 118-129. [CrossRef]

28. Ghezzo, M.; Guerzoni, S.; Cucco, A.; Umgiesser, G. Changes in Venice Lagoon dynamics due to construction of mobile barriers. Coast. Eng. 2010, 57, 694-708. [CrossRef] 
29. Lopez-Castejon, F. Caracterización de la hidrodinámica del Mar Menor y los flujos de intercambio con el Mediterráneo mediante datos in situ y modelado numérico. Ph.D. Thesis, Technical University of Cartagena, Cartagena, Spain, 2017.

30. Pérez-Ruzafa, A.; Fernández, A.I.; Marcos, C.; Gilabert, J.; Quispe, J.I.; García-Charton, J.A. Spatial and temporal variations of hydrological conditions, nutrients and chlorophyll a in a Mediterranean coastal lagoon (Mar Menor, Spain). Hydrobiologia 2005, 550, 11-27. [CrossRef]

31. Pérez-Ruzafa, Á. Estudio ecológico y bionómico de los poblamientos bentónicos del Mar Menor (Murcia, SE de España). Ph.D. Thesis, Universidad de Murcia, Murcia, Spain, 1989.

32. Martínez-Alvarez, V.; Gallego-Elvira, B.; Maestre-Valero, J.F.; Tanguy, M. Simultaneous solution for water, heat and salt balances in a Mediterranean coastal lagoon (Mar Menor, Spain). Estuar. Coast. Shelf Sci. 2011, 91, 250-261. [CrossRef]

33. Webster, I.T. The hydrodynamics and salinity regime of a coastal lagoon-The Coorong, Australia-Seasonal to multi-decadal timescales. Estuar. Coast. Shelf Sci. 2010, 90, 264-274. [CrossRef]

34. Zemlys, P.; Ferrarin, C.; Umgiesser, G.; Gulbinskas, S.; Bellafiore, D. Investigation of saline water intrusions into the Curonian Lagoon (Lithuania) and two-layer flow in the Klaipeda Strait using finite element hydrodynamic model. Ocean Sci. 2013, 9, 573-584. [CrossRef]

35. Umgiesser, G.; Canu, D.M.; Cucco, A.; Solidoro, C. A finite element model for the Venice Lagoon. Development, set up, calibration and validation. J. Mar. Syst. 2004, 51, 123-145. [CrossRef]

36. Bellafiore, D.; Umgiesser, G. Hydrodynamic coastal processes in the North Adriatic investigated with a 3D finite elements model. Ocean Dyn. 2010, 60, 255-273. [CrossRef]

37. Ferrarin, C.; Bergamasco, A.; Umgiesser, G.; Cucco, A. Hydrodynamics and spatial zonation of the Capo Peloro coastal system (Sicily) through 3-D numerical modeling. J. Mar. Syst. 2013, 117, 96-107. [CrossRef]

38. Bellafiore, D.; Umgiesser, G.; Cucco, A. Modeling the water exchanges between the Venice Lagoon and the Adriatic Sea. Ocean Dyn. 2008, 58, 397-413. [CrossRef]

39. Hesse, C.; Stefanova, A.; Krysanova, V.; Bielecka, M.; Domnin, D.A.; Lloret, J.; Loboda, N.; Sousa, L. LAGOONS 2013. Results of Climate Impact Assessment-Application for Four Lagoon Catchments. LAGOONS Report D5.1, 107p. Available online: http:/ /lagoons.biologiaatua.net/?page_id=702 (accessed on 29 March 2018).

40. Pérez-Ruzafa, A.; Marcos, C.; Quispe, J.I.; García-Sánchez, M.; López-Capel, A.; Barba, A.; Oliva, J.; Martínez-Sánchez, M.J.; Pérez-Sirvent, C.; Martínez-Paz, J.M. Study for the Dispersion of the Existing Spills in the Mar Menor Coastal Lagoon and The Cost-Efficiency Analysis of the Lack of Application of Correction Measurements for the Improvement of the Lagoon Water Quality; Entidad: Consejeria de Agricultura y Agua; Informe Final: Murcia, Spain, 2010.

41. Fratianni, C.; Simoncelli, S.; Pinardi, N.; Cherchi, A.; Grandi, A.; Dobricic, S. Mediterr. RR 1955-2015 (Version 1). Data Set; Copernicus Monitoring Environment Marine Service (CMEMS): Vincennes, France, 2015. [CrossRef]

42. Oddo, P.; Pinardi, N.; Zavatarelli, M.; Coluccelli, A. The Adriatic basin forecasting system. Acta Adriat. 2006, 47, 169-184.

43. Burchard, H.; Bolding, K.; Villarreal, M. GOTM, a General Ocean Turbulence Model: Theory, Implementation and Test Cases; Rep. EUR18745; Space Applications Institute: Ahmedabad, Gujarat, 1999.

44. Arévalo, L. El Mar Menor como sistema forzado por el Mediterráneo. Control hidráulico y agentes fuerza. Boletín del Inst. Español de Oceanogr. 1988, 5, 63-95.

45. Pérez-Ruzafa, A.; Marcos, C.; Bernal, C.M.; Quintino, V.; Freitas, R.; Rodrigues, A.M.; García-Sánchez, M.; Pérez-Ruzafa, I.M. Cymodocea nodosa vs. Caulerpa prolifera: Causes and consequences of a long term history of interaction in macrophyte meadows in the Mar Menor coastal lagoon (Spain, southwestern Mediterranean). Estuar. Coast. Shelf Sci. 2012, 110, 101-115. [CrossRef]

46. Chubarenko, B.; Koutitonsky, V.G.; Neves, R.; Umgiesser, G. Modeling concepts. In Coastal Lagoons: Ecosystem Processes and Modeling for Sustainable Use and Development; CRC Press: Boca Ratón, FL, USA, 2005; pp. 231-306. ISBN 9781566706865.

47. Cucco, A.; Umgiesser, G. Modeling the Venice Lagoon residence time. Ecol Model. 2006, 193, 34-51. [CrossRef]

48. Arndt, E.A. Ecological, physiological and historical aspects of brackish water fauna distribution. In Reproduction, Genetics and Distributions of Marine Organisms; Ryland, J.S., Tyler, P.A., Eds.; Olsen \& Olsen: Fredensborg, Denmark, 1989; pp. 327-338.

49. McLusky, D.S. Estuarine benthic ecology: A European perspective. Aust. J. Ecol. 1999, 24, 302-311. [CrossRef] 
50. Petit, G. Introduction à l'étude écologique des étangs méditerranéens. Vie Milieu 1953, 4, 569-604.

51. Aguesse, P. La classification des eaux poikilohalines, sa difficulté en Camargue. Nouvelle tentative de classification. Vie et Milieu 1957, 8, 341-365.

52. D'Ancona, U. The classification of brackish waters with reference to the North Adriatic lagoons. Arch. Oceanogr. Limnol. 1959, 11, 93-109.

53. Guelorget, O.; Perthuisot, J.P. Le domaine paralique. Expressions géologiques, biologiques et économiques du confinement. Travaux du Laboratoire de Géologie 1983, 16, 1-136.

54. Kjerfve, B. Coastal Lagoons. In Coastal Lagoon Processes; Elsevier Oceanography Series 60; Kjerfve, B., Ed.; Elsevier: Amsterdam, The Netherlands, 1994; pp. 1-8.

55. Pérez-Ruzafa, Á.; Marcos, C.; Pérez-Ruzafa, I.M. Recent advances in coastal lagoons ecology: Evolving old ideas and assumptions. Transit. Waters Bull. 2011, 5. [CrossRef]

56. Pérez-Ruzafa, A.; Marcos, C. Colonization rates and dispersal as essential parameters in the confinement theory to explain the structure and horizontal zonation of lagoon benthic assemblages. Rapp. Comm. Int. Mer Médit. 1992, 33, 100.

57. Pérez-Ruzafa, A.; Marcos, C. La teoría del confinamiento como modelo para explicar la estructura y zonación horizontal de las comunidades bentónicas en las lagunas costeras. Publ. Espec. Inst. Esp. Oceanogr. 1993, 11, 347-358.

58. Pérez-Ruzafa, A.; Mompeán, M.C.; Marcos, C. Hydrographic, geomorphologic and fish assemblage relationships in coastal lagoons. Hydrobiologia 2007, 577, 107-125. [CrossRef]

59. Van Rijn, L.C. Principles of Sediment Transport in Rivers, Estuaries and Coastal Sea; Aqua Publications: Amsterdam, The Netherlands, 1993.

60. Soulsby, D. Dynamics of Marine Sands; ThomasTelford: London, UK, 1997.

61. Hjulstrom, F. Studies of the morphological activity of rivers as illustrated by the River Fyris. Bull. Geol. Inst. 1935, 25, 221-527.

62. Humphries, S. Filter feeders and plankton increase particle encounter rates through flow regime control. Proc. Natl. Acad. Sci. USA 2009, 106, 7882-7887. [CrossRef] [PubMed]

63. Tytell, E. Filter feeding at intermediate reynolds number. J. Exp. Biol. 2009, 212, VI. [CrossRef]

64. Pérez-Ruzafa, A. El papel de la conectividad restringida en la construcción de los ecosistemas marinos semiaislados: El ejemplo de las lagunas costeras y los archipiélagos. Revista de la Academia Canaria de Ciencias 2015, 27, 411-456.

65. Fujioka, K.; Fukuda, H.; Furukawa, S.; Tei, Y.; Okamoto, S.; Ohshimo, S. Habitat use and movement patterns of small (age-0) juvenile Pacific bluefin tuna (Thunnus orientalis) relative to the Kuroshio. Fish. Oceanogr. 2018, 27, 185-198. [CrossRef]

66. Beraud, C.; Van Der Molen, J.; Armstrong, M.; Hunter, E.; Fonseca, L.; Hyder, K. The influence of oceanographic conditions and larval behaviour on settlement success-The European sea bass Dicentrarchus labrax (L.). ICES J. Mar. Sci. 2018, 75, 455-470. [CrossRef]

67. Vallès, H. Parrotfish recruitment revisited: A key role for sea surface currents. Environ. Biol. Fishes 2017, 100, 1649-1657. [CrossRef]

68. Neufeld, K.; Watkinson, D.A.; Tierney, K.; Poesch, M.S. Incorporating asymmetric movement costs into measures of habitat connectivity to assess impacts of hydrologic alteration to stream fishes. Divers. Distrib. 2018, 24, 593-604. [CrossRef]

69. Lae, R. Changes in fish and crustacean communities of a tropical lagoon, lake Togo, submitted to alternate phases of opening and closing belt. Aquat. Living Resour. 1994, 7, 165-179.

70. Pombo, L.; Elliot, M.; Rebelo, J.E. Changes in the fish fauna of the Ria de Aveiro estuarine lagoon (Portugal) during the twentieth century. J. Fish Biol. 2002, 61 (Suppl. A), 167-181. [CrossRef]

71. Castro, C. Mejoramiento de lagunas costeras: Algunos ejemplos de México. In Management of Coastal Lagoon Fisheries; FAO Studies and Reviews, GFCM No. 61; Kapetsky, J.M., Lasserre, G., Eds.; FAO: Rome, Italy, 1984; pp. 695-708.

72. Peja, N.; Vaso, A.; Miho, A.; Rakaj, N.; Crivelli, A.J. Characteristics of Albanian lagoons and their fisheries. Fish. Res. 1996, 27, 215-225. [CrossRef]

73. Marcos, C.; Torres, I.; López-Capel, A.; Pérez-Ruzafa, A. Long term evolution of fisheries in a coastal lagoon related to changes in lagoon ecology and human pressures. Rev. Fish Biol. Fish. 2015, 25, 689-713. [CrossRef]

74. Joyeux, J.C.; Ward, A.B. Constraints on Coastal Lagoon Fisheries. Adv. Mar. Biol. 1998, 34, 74-199. 
75. Butigieg, J. La despoblación del Mar Menor y sus causas. Boletín de Pescas. Dirección General de Pesca del Ministerio de Marina. Instituto Español de Oceanografia 1927, 133, 251-286.

76. Navarro, F. Observaciones sobre el Mar Menor (Murcia). Notas y resumenes del Instituto Español de Oceanografía Serie II 1927, 16, 1-63.

77. May, N.; Trent, L.; Pristas, P.J. Relation of fish catches in gill nets to frontal periods. Fish. Bull. 1976, 74, 449-453.

78. Walker, M.G.; Jones, F.R.H.; Arnold, G.P. The movements of plaice (Pleuronectes platessa L.) tracked in the open sea. ICES J. Mar. Sci. 1958, 38, 58-86. [CrossRef]

79. Reed, M. A multidimensional continuum model of fish behavior. Ecol. Model. 1983, 20, 311-322. [CrossRef]

80. Pérez-Ruzafa, A.; Marcos, C.; Pérez-Ruzafa, I.M. When maintaining ecological integrity and complexity is the best restoring tool: The case of the Mar Menor lagoon. In: Quintana, X.; Boix, D., Gascón, S. and Sala, J. (coords). Protecting and restoring the salt marshes and seagrasses in the lagoon of Venice. Management and restoration of Mediterranean coastal lagoons in Europe. Recer. i territorio 2018, 10, 67-95.

81. Quignard, J.P. Les caracteristiques Biologiques et environmentales des lagunes en tant que base biologique de l'amenagement des pecheries. In Management of Coastal Lagoon Fisheries; FAO Studies and Reviews, GFCM No. 61; Kapetsky, J.M., Lasserre, G., Eds.; FAO: Rome, Italy, 1984; pp. 4-38.

82. Rossi, G. Management of aquaculture and fishing in the Scardovari fishery (Po River delta, Italy). In Management of Coastal Lagoon Fisheries; FAO Studies and Reviews, GFCM No. 61; Kapetsky, J.M., Lasserre, G., Eds.; FAO: Rome, Italy, 1984; pp. 441-460.

83. Dye, A.H. Meiobenthos in intermittently open/closed coastal lakes in New South Wales: Spatial and temporal patterns in densities of major taxa. Mar. Freshw. Res. 2005, 56, 1055-1067. [CrossRef]

(C) 2018 by the authors. Licensee MDPI, Basel, Switzerland. This article is an open access article distributed under the terms and conditions of the Creative Commons Attribution (CC BY) license (http:/ / creativecommons.org/licenses/by/4.0/). 